

MARCELO PAULO DE ARRUDA

A INFLUÊNCIA DE CARACTERÍSTICAS DA AUDITORIA INDEPENDENTE NA QUALIDADE DA INFORMAÇÃO CONTÁBIL

JOÃO PESSOA-PB 


\section{A INFLUÊNCIA DE CARACTERÍSTICAS DA AUDITORIA INDEPENDENTE NA QUALIDADE DA INFORMAÇÃO CONTÁBIL}

Dissertação apresentada como requisito à obtenção do título de Mestre em Ciências Contábeis do Programa Multiinstitucional e Inter-Regional de Pós-Graduação em Ciências Contábeis da Universidade de Brasília, da Universidade Federal da Paraíba e da Universidade Federal do Rio Grande do Norte.

Linha de Pesquisa: Contabilidade e Mercados Financeiros

Orientador: Prof. Dr. Wenner Glaucio Lopes Lucena 
A779i Arruda, Marcelo Paulo de.

A influência de características da auditoria independente na qualidade da informação contábil / Marcelo Paulo de Arruda.João Pessoa, 2016.

$60 f$.

Orientador: Wenner Glaucio Lopes Lucena

Dissertação (Mestrado) - UnB-UFPB-UFRN

1. Contabilidade. 2. Contabilidade e mercados financeiros. 3. Auditoria. 4. Qualidade da auditoria. 5. Qualidade da informação contábil. 


\section{A INFLUÊNCIA DE CARACTERÍSTICAS DA AUDITORIA INDEPENDENTE NA QUALIDADE DA INFORMAÇÃO CONTÁBIL}

Dissertação apresentada como requisito à obtenção do título de Mestre em Ciências Contábeis do Programa Multiinstitucional e Inter-Regional de Pós-Graduação em Ciências Contábeis da Universidade de Brasília, da Universidade Federal da Paraíba e da Universidade Federal do Rio Grande do Norte.

Prof. Dr. Wenner Glaucio Lopes Lucena

Orientador - Programa Multiinstitucional e Inter-regional de Pós-Graduação em Ciências Contábeis - UnB/UFPB/UFRN

Prof. Dr. Paulo Roberto Nóbrega Cavalcante

Examinador Interno - Programa Multiinstitucional e Inter-regional de Pós-Graduação em Ciências Contábeis - UnB/UFPB/UFRN

Prof. Dr. José Ribamar Marques de Carvalho Examinador Externo - Universidade Federal de Campina Grande 
A minha esposa Larissa e aos meus pais Edilson e Suely, pelo apoio incondicional em todos os momentos da minha vida, sejam estes felizes ou difíceis. Amo vocês! 


\section{AGRADECIMENTOS}

Ao meu Deus, por sempre me sustentar em todos os momentos e me mostrar os caminhos que devo seguir.

A minha esposa Larissa, por todo o amor, amizade, carinho, atenção, conselhos, entre outras inúmeras contribuições, onde sem as quais não seria possível a conclusão de mais uma etapa da minha vida acadêmica. Sou grato a Deus por ter você ao meu lado e espero um dia poder retribuir tudo isto meu amor. Te amo.

Aos meus pais Edilson e Suely, por todos os conselhos, por mostrarem os caminhos que devo seguir e por todo o suporte dado a mim, por sempre estarem ao meu lado, principalmente nos momentos que mais precisei. Obrigado por tudo! Amo vocês!

Ao meu irmão Gustavo e as minhas irmãs Suelen, Ana Letícia (Lelê) e Maria Júlia (Juju), pelas alegrias de todos os momentos com vocês. Não tenho palavras para descrever o que sinto por todos vocês.

Ao meu amigo e orientador Professor Dr. Wenner Glaucio Lopes Lucena, pela sua instimável contribuição para a minha vida pessoal e profissional, pelas portas abertas para mim durante o mestrado. Serei eternamente grato. Muito obrigado!

Aos meus demais familiares, meu avô Valdy, minha tia Penha, Marquinhos, Iana, tios, tias, primos e primas, por todo o apoio e incentivo. Obrigado a todos!

Aos meus colegas da última turma de mestrado do Programa Multiinstitucional e Interregional de Pós-graduação em Ciências Contábeis UnB/UFPB/UFRN do Núcleo Nordeste, André, Inajá, Ana Karla, Victor Ranieri, Polyandra, Agamenon, Camila, Fabiana, Leandro, Roberto e Victor Godeiro, por todos os momentos que passamos juntos durante as disciplinas. Vocês ficarão sempre em minhas memórias, que Deus abençoe o caminho de cada um. Forte abraço!

A todos os professores do Programa Multiinstitucional e Inter-regional de Pós-graduação em Ciências Contábeis UnB/UFPB/UFRN: Dr. Adilson de Lima Tavares, Dr. Aldo Leonardo Cunha Callado, Dra. Aneide Oliveira Araújo, Dr. Edilson Paulo, Dra. Márcia Reis Machado, Dr. Paulo Aguiar do Monte, Dr. Paulo Amilton Maia Leite Filho, Dr. Paulo Roberto Nóbrega Cavalcante e Dr. Wenner Glaucio Lopes Lucena.

Ao meu amigo João Marcelo, pela apoio para que eu pudesse iniciar esta etapa. Sem a sua ajuda nada disso seria possível, serei eternamente grato. Grande Abraço!

Aos meus amigos e colegas de profissão ou pesquisa, em especial a Thiago Pena, Nyag Teixeira e Felipe Pontes, pela ajuda de vocês durante a realização deste estudo. Que Deus os abençoe.

Aos meus irmãos da Primeira Igreja Batista de João Pessoa, pelas orações destinadas a mim. Que Deus abençoe a cada um. Amo vocês! 
Aos professores Dr. Paulo Roberto da Cunha (FURB), Dr. Guillermo Braunbeck (USP) e Dra. Ana Maria Rodrigues (Universidade de Coimbra) pelas contribuições dadas a esta dissertação nos consórcios mestral em que participei.

Enfim, a todos os que contribuíram de alguma forma para a conclusão deste estudo. Meus sinceros agradecimentos! 
"Pois dele, por ele e para ele são todas as coisas. A ele seja a glória para sempre! Amém."

Romanos 11:36 NVI 


\section{RESUMO}

A auditoria contábil se mostra como ferramenta importante na detecção de falhas e erros possivelmente contidas nas relatórios financeiros. As pesquisas nessa área tem se concentrado em verificar as características de auditoria, tratadas como proxies para qualidade da auditoria, discutindo estas. Mediante a literatura existente, infere-se que os serviços de auditoria pode minimizar os conflitos de agência, bem como a assimetria informacional existente entre as partes relacionadas a companhia. Com isto, as características da auditoria podem afetar na qualidade da informação contábil das companhias, mensurada mediante os seus atributos tratados por Dechow, Ge e Schrand (2010). O presente estudo buscou verificar a influência de características da auditoria independente (tamanho da firma, período de relacionamento entre a firma de auditoria e o cliente, serviços não relacionados a auditoria, presença do comitê de auditoria e o tempo de emissão do relatório de auditoria) sobre a qualidade da informação contábil (conservadorismo, qualidade na mensuração dos accruals e value relevance). Com base no modelo de Dechow e Dichev (2002), pode-se verificar que mais tempo de relacionamento entre a firma de auditoria e o cliente melhor a qualidade na mensuração dos accruals, corroborando com estudos anteriores (MYERS; MYERS; OMER, 2003; CHEN; LIN; LIN, 2008). Em relação ao value relevance, mensurado pelo modelo de Ohlson (1992), infere-se que as companhias auditadas por firmas de auditoria que prestam serviços não relacionados a sua atividade principal apresentam influência positiva na precificação das ações, o que pode está relacionado a sinalização dada ao mercado de possível conhecimento acerca de outras informações, mediante tais serviços, da companhia auditada. A mesma característica da auditoria impacta negativamente no nível de conservadorismo, conforme modelo adaptado do Ball e Shivakumar (2002). Outra variável que impacta no conservadorismo contábil foi o tempo de relacionamento entre a firma de auditoria e o cliente, verificando-se que maior tempo de relacionamento afetava positivamente no nível de conservadorismo, aumentando tal qualidade da informação contábil. Com isto, percebe-se que determinadas características da auditoria independente afetam na qualidade da informação contábil. As principais limitações deste estudo foram a ausência de dados, acarretando na diminuição no número de observações e na impossibilidade de estimação das regressões em dados em painel balanceado. Para futuras pesquisas, sugere-se a criação de um índice de vise captar a influência de diversas características de auditoria independente na qualidade da informação contábil, além da análise de companhias localizadas em outros países, afim de comparar os resultados com o presente estudo.

Palavras-chave: Auditoria; Qualidade da Auditoria; Qualidade da Informação Contábil. 


\begin{abstract}
The audit shows how important tool fault detection and errors possibly contained in financial reports. Research in this area has focused on checking audit features, treated as proxies for audit quality, discussing these. Through the literature, it appears that the audit services can minimize the agency conflicts as well as the existing information asymmetry between the parties related to the company. With this, the audit features can affect the quality of accounting information of companies, measured by its attributes handled by Dechow, Ge and Schrand (2010). This study looked at the influence of characteristics of the independent audit (firm size, relationship period between the auditing firm and the client, not services related to audit, presence of audit committee and the time of issuance of the audit report) on the quality of accounting information (conservatism, quality in the measurement of accruals and value relevance). Based on the model of Dechow and Dichev (2002), it can be seen that more time relationship between the auditing firm and the best customer quality in the measurement of accruals, corroborating previous studies (MYERS; MYERS; OMER, 2003; CHEN; LIN, LIN, 2008). Regarding the value relevance, measured by the Ohlson's model (1992) inferred that companies audited by auditing firms that do not provide services related to its core business have positive impact on the pricing of shares, which may relates to signaling given the market possible knowledge of other information by such services, the audited company. The same characteristic of the audit negatively impacts the level of conservatism, as adapted model of Ball and Shivakumar (2002). Another variable that impacts the accounting conservatism was the relationship of time between the auditing firm and the client, where it was found that most relationship time positively affected the level of conservatism, increasing such quality of accounting information. With this, it is clear that certain auditing features independent affect on the earnings quality. The main limitations of this study were the lack of data, resulting in a decrease in the number of observations and the estimation of impossibility of regressions on data on balanced panel. For future research, we suggest the establishment of an index aims to capture the influence of different characteristics independent audit on the quality of accounting information, as well as analysis companies located in other countries in order to compare the results with the present study.
\end{abstract}

Keywords: Audit; Audit Quality; Earnings Quality. 


\section{LISTA DE TABELAS}

Tabela 1 - Estatísticas Descritivas - Modelo Conservadorismo ........................................ 38

Tabela 2 - Estatísticas Descritivas - Modelo Qualidade na Mensuração dos Accruals....... 38

Tabela 3 - Estatísticas Descritivas - Modelo Value Relevance .......................................... 38

Tabela 4 - Quantidade de companhias auditadas por Big 4 x Outras Firmas (Não Big 4).. 39

Tabela 5 - Quantidade de firmas de auditoria que prestaram serviços não relacionados a



Tabela 6 - Quantidade de companhias com presença ou não do Comitê de Auditoria ....... 39

Tabela 7 - Análise da influência do Tamanho da Firma de Auditoria sobre o Conservadorismo Condicional

Tabela 8 - Análise da influência do Período de Relacionamento entre a Firma de Auditoria e o cliente sobre o Conservadorismo Condicional

Tabela 9 - Análise da influência de Serviços não Relacionados a Auditoria sobre o Conservadorismo Condicional

Tabela 10 - Análise da Presença do Comitê de Auditoria sobre o Conservadorismo



Tabela 11 - Análise do Tempo de Emissão do Relatório de Auditoria sobre o

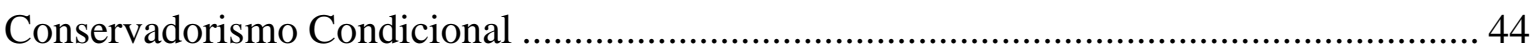

Tabela 12 - Análise da influência do Tamanho da Firma de Auditoria sobre a Qualidade da Mensuração dos Accruals

Tabela 13 - Análise da influência do Período de Relacionamento entre a Firma de Auditoria e o cliente sobre a Qualidade da Mensuração dos Accruals. 46

Tabela 14 - Análise da influência de Serviços não Relacionados a Auditoria sobre a Qualidade da Mensuração dos Accruals 46

Tabela 15 - Análise da influência da Presença de Comitê de Auditoria sobre a Qualidade da Mensuração dos Accruals

Tabela 16 - Análise da influência do Tempo de Emissão do Relatório de Auditoria sobre a

Qualidade da Mensuração dos Accruals

Tabela 17 - Análise da influência do Tamanho da Firma de Auditoria sobre o Value Relavance.

Tabela 18 - Análise da influência do Período de Relacionamento entre a Firma de Auditoria e o cliente sobre o Value Relevance

Tabela 19 - Análise da influência dos Serviços não Relacionados a Auditoria sobre o Value

Relevance.

Tabela 20 - Análise da influência da Presença do Comitê de Auditoria sobre o Value Relevance.

Tabela 21 - Análise da influência do Tempo de Emissão do Relatório de Auditoria sobre o Value Relevance.

Tabela 22 - Análise da influência do Tempo de Emissão do Relatório de Auditoria sobre o Value Relevance (segregados em grupos) 


\section{LISTA DE ABREVIATUVAS E SIGLAS}

ANATEL - Agência Nacional de Telecomunicações

ANS - Agência Nacional de Saúde Suplementar

BACEN - Banco Central do Brasil

CVM - Comissão de Valores Mobiliários

IFAC - International Federation of Accountants

IASB - International Accounting Standards Boards

PCGA - Principios Contábeis Geralmente Aceitos

PCAOB - Public Company Accounting Oversight Board

SEC - Securities and Exchange Commission

SUSEP - Superintendência de Seguros Privados 


\section{SUMÁRIO}

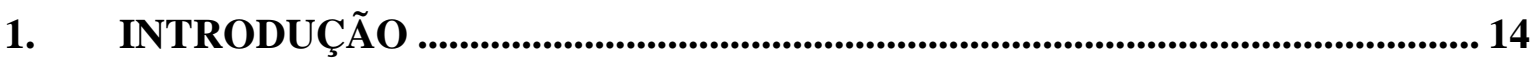

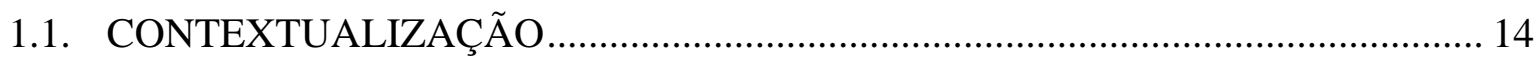

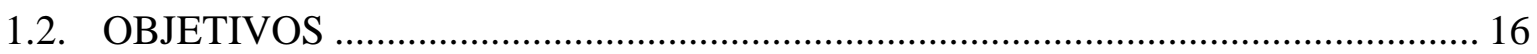

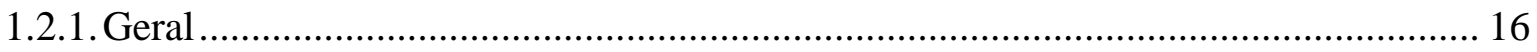

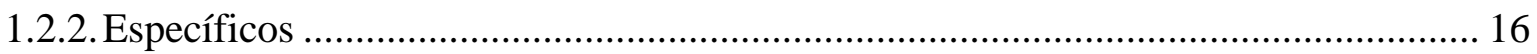

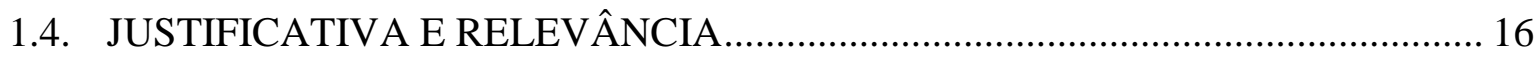

2. REFERENCIAL TEÓRICO .............................................................................................. 18

2.1. AUDITORIA INDEPENDENTE E SUA IMPORTÂNCIA ………………………..... 18

2.2. QUALIDADE DA AUDITORIA INDEPENDENTE ……………....................... 20

2.2.1. Tamanho da Firma de auditoria ............................................................................. 21

2.2.2. Período de relacionamento entre a firma de auditoria e o cliente .............................. 21

2.2.3. Serviços não relacionados a auditoria .................................................................. 22

2.2.4. Presença do Comitê de Auditoria............................................................................. 23

2.2.5. Tempo de Emissão do Relatório de Auditoria …………………………………….... 23

2.3. QUALIDADE DA INFORMAÇÃO CONTÁBIL ……………………………….... 24

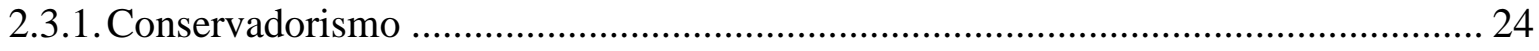

2.3.2. Qualidade na mensuração dos accruals ................................................................ 26

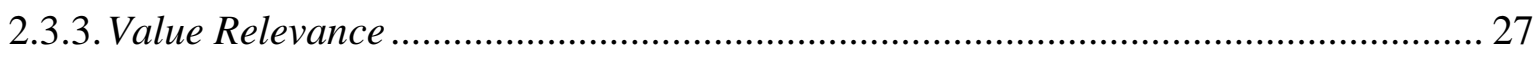

2.4 PESQUISAS EMPÍRICAS SOBRE OS TEMAS PESQUISADOS ........................... 28

3. PROCEDIMENTOS METODOLÓGICOS ....................................................... 30

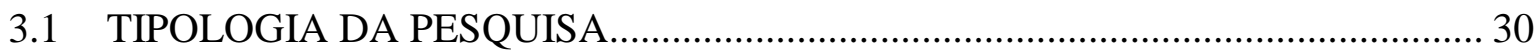

3.2 PLANO AMOSTRAL E PROCEDIMENTOS PARA A COLETA DE DADOS .... 30

3.3 DEFINIÇÃO DOS MODELOS EMPREGADOS E VARIÁVEIS ............................. 32

3.3.1 Modelo de mensuração do nível de conservadorismo .............................................. 32

3.3.2 Modelo de mensuração da qualidade de mensuração dos accruals ......................... 33

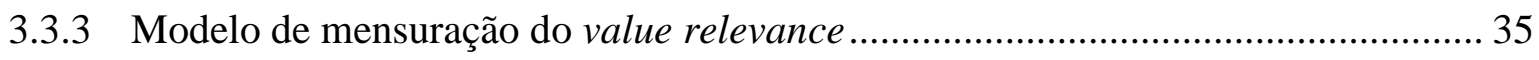

3.3.4 Definição das variáveis da qualidade da auditoria .................................................... 36

4. ANÁLISE E INTERPRETAÇÃO DOS RESULTADOS ....................................38

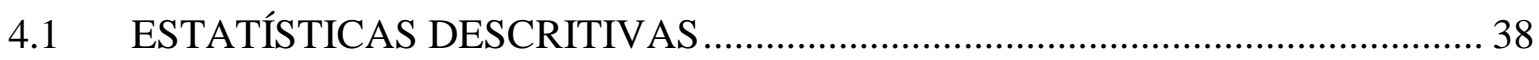

4.2 ANÁLISE DOS RESULTADOS DA PESQUISA ………………………............ 39

4.2.1 Análise da influência das características da auditoria independente sobre o

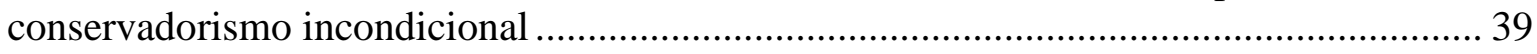


4.2.1.1 Análise da influência do tamanho da firma de auditoria independente sobre o conservadorismo incondicional....

4.2.1.2 Análise da influência do período de relacionamento entre a firma de auditoria independente e a companhia auditada sobre o conservadorismo incondicional 40

4.2.1.3 Análise da influência da realização de serviços de não auditoria pela firma de auditoria independente sobre o conservadorismo incondicional 41

4.2.1.4 Análise da influência da existência de comitê de auditoria na companhia auditada sobre o conservadorismo incondicional

4.2.1.5 Análise da influência do tempo de emissão do relatório de auditoria independente sobre o conservadorismo incondicional

4.2.2 Análise da influência das características da auditoria independente sobre a qualidade na mensuração dos accruals

4.2.2.1 Análise da influência do tamanho da firma de auditoria independente sobre a qualidade na mensuração dos accruals .....

4.2.2.2 Análise da influência do período de relacionamento entre a firma de auditoria independente e a companhia auditada sobre a qualidade na mensuração dos accruals ...... 45

4.2.2.3 Análise da influência da realização de serviços de não auditoria pela firma de auditoria independente sobre a qualidade na mensuração dos accruals

4.2.2.4 Análise da influência da existência de comitê de auditoria na companhia auditada sobre a qualidade na mensuração dos accruals....

4.2.2.5 Análise da influência do tempo de emissão do relatório de auditoria independente sobre a qualidade na mensuração dos accruals .

4.2.3 Análise da influência das características da auditoria independente sobre o value relevance

4.2.3.1 Análise da influência do tamanho da firma de auditoria independente sobre o value relevance

4.2.3.2 Análise da influência do tempo de relacionamento entre a firma de auditoria e o cliente sobre o value relevance.

4.2.3.3 Análise da influência da realização de outros serviços não relacionados a auditoria pela firma de auditoria independente sobre o value relevance.

4.2.3.4 Análise da influência da existência de comitê de auditoria na companhia auditada sobre o value relevance

4.2.3.5 Análise da influência do tempo de emissão do relatório de auditoria independente sobre o value relevance

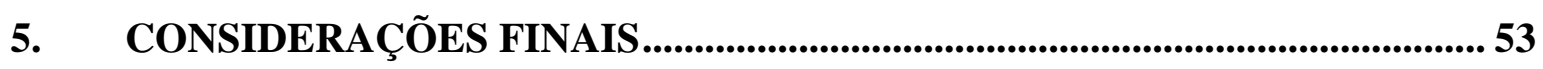

REFERÊNCIAS BIBLIOGRÁFICAS ...................................................................... 55 


\section{INTRODUÇÃO}

\subsection{CONTEXTUALIZAÇÃO}

A informação contábil se constitui em um ponto importante na tomada de decisões em diversas atividades empresariais, como na avaliação de desempenho da empresa e dos gestores, gestão de custos, política de financiamentos e de investimentos, entre outras, bem como instrumento de monitoramento por parte dos órgãos reguladores (WATTS; ZIMMERMAN, 1986). Diante da relevância da Contabilidade, tem-se ampliado a preocupação com a qualidade das informações contábeis reportadas.

Entende-se que a informação contábil apresentada pelas companhias é afetada tanto por diversas características relacionadas a empresa, como, por exemplo, auditoria independente e governança corporativa, quanto por características relacionadas ao mercado no qual a mesma está inserida, tais como, políticas econômicas adotadas pelos governos locais, processo de regulação e monitoramento do mercado financeiro e de capitais e fontes de captação de recursos das empresas, conforme exposto por Dechow, Ge e Schrand (2010). A auditoria independente surge como ferramenta na qual visa atribuir maior confiabilidade as demonstrações contábeis reportadas pelas companhias, capaz de proporcionar um menor risco aos tomadores de decisões acerca da empresa e gerando maior confiança aos operadores do mercado mobiliário.

Segundo Boynton, Johnson e Kell (2002), uma auditoria de demonstrações contábeis envolve entendimento do negócio e do setor de atividades do cliente, bem como obtenção e avaliação de evidências que permitam que o auditor verifique se as demonstrações contábeis elaboradas pela gestão realmente apresentam adequadamente a posição financeira, o resultado das operações e os fluxos de caixa da entidade, de acordo com os Princípios Contábeis Geralmente Aceitos.

Mediante o exposto, pode-se inferir que a eficiência do serviço de auditoria executado pode depender, por exemplo, da capacidade da auditoria externa em entender sobre os negócios da empresa auditada, sendo assim, supõem-se que firmas de auditoria com maior investimento em treinamentos apresentam maior probabilidade em executar um serviço de "maior qualidade" que firmas cujo investimento em treinamentos seja baixo. Nesse sentido, verifica-se que a qualidade dos serviços de auditoria depende de diversas características, principalmente relacionadas com o próprio auditor ou firma de auditoria, conforme abordado por Francis (2004). Tais características são tratadas na literatura como as características qualitativas da auditoria, sendo utilizadas como proxies 
para a qualidade da auditoria. Dentre estas proxies pode-se citar, conforme exposto na literatura existente, as seguintes características: tamanho da firma de auditoria (DEANGELO, 1981; BEHN; CHOI; KANG, 2009; RODRÍGUEZ; ALEGRÍA, 2012; LEE; LEE, 2013), especialização da auditoria (CRASWELL; FRANCIS; TAYLOR, 1995; OWHOSO; MESSIER; LYNCH JR., 2002; BEHN; CHOI; KANG, 2009; SUN; LIU, 2013), tempo de emissão do relatório de auditoria (LEVENTIS, CARAMANIS, 2005; AL-AHMI, 2008), entre outros.

A partir dos estudos supracitados é possível perceber que uma alta qualidade da auditoria pode acarretar melhora na qualidade dos relatórios contábeis evidenciados, conforme defendido por Iatridis (2011), ao analisar a relação entre tamanho da firma de auditoria (proxy para qualidade da auditoria) e a evidenciação contábil defende este entendimento. Houmes, Foley e Cebula (2013) corroboram com este autor, ao afirmarem que o valor da informação contábil é uma função da sua credibilidade, e que o objetivo central da auditoria é melhorar a qualidade da informação financeira. Porém, a grande dificuldade quando se trata de qualidade da informação contábil é identificar quais características (atributos) melhoram a qualidade da informação reportada, pois, conforme Paulo, Cavalcante e Paulo (2013), um evento ou transação mensurado ou evidenciado de acordo com um determinado critério contábil pode ser considerado por um agente como uma informação de boa qualidade, enquanto outro agente econômico pode não atribuir a mesma qualidade.

Neste sentido, diversas pesquisas (BECKER et al., 1998; PIOT, 2005; RUDDOCK; TAYLOR; TAYLOR, 2006) analisaram a influência da qualidade da auditoria independente sobre a qualidade da informação contábil. Percebe-se que as pesquisas voltadas ao tema focam em apenas uma dimensão da qualidade da auditoria (DEANGELO, 1981; LEVENTIS; CARAMANIS, 2005; SUN; LIU, 2013) ou em um atributo da informação contábil (PIOT, 2005; CHAN; LAU; NG, 2011; PAULO, 2012; SUN; LIU, 2013), o que limita a abrangência das evidências encontradas ou, em outros termos, não conseguem captar adequadamente a influência da atividade da auditoria.

Diante do exposto, tem-se o seguinte problema de pesquisa: Qual a influência de características da qualidade da auditoria independente na qualidade da informação contábil? 


\subsection{OBJETIVOS}

\subsubsection{Geral}

O objetivo geral deste trabalho é verificar a influência de características da auditoria independente na qualidade das informações contábeis nas companhias abertas brasileiras.

\subsubsection{Específicos}

Para atingir o objetivo geral da pesquisa, faz-se necessário alcançar os objetivos específicos abaixo:

a. Evidenciar o papel dos auditores independentes na validação da informação contábil entregue via relatórios financeiros;

b. Verificar a influência do tamanho da firma de auditoria na qualidade da informação contábil;

c. Avaliar de que forma o período de relacionamento entre a firma de auditoria e cliente afeta na qualidade da informação contábil;

d. Averiguar como os serviços de não auditoria, prestados por firmas de auditoria, afetam na qualidade da informação contábil;

e. Analisar a relação entre a existência do comitê de auditoria e a qualidade da informação contábil;

f. Investigar a influência do tempo de emissão do relatório de auditoria na qualidade da informação contábil;

\subsection{JUSTIFICATIVA E RELEVÂNCIA}

A partir dos grandes escândalos corporativos conhecidos e divulgados mundialmente, como o caso da Enron Corporation e da WorldCom, marcadas por fraudes contábeis, a auditoria revela-se como ferramenta essencial para a identificação destes eventos, dando confiabilidade aos relatórios reportados pelas empresas e garantindo, de certa forma, um melhor funcionamento dos mercados de capitais.

Porém, conforme analisado em alguns estudos (DEANGELO, 1981; CRASWELL; FRANCIS; TAYLOR, 1995; OWHOSO; MESSIER JR.; LYNCH LR., 2001; LEVENTIS; CARAMANIS, 2005), a auditoria independente é afetada por características qualitativas, que irão influenciar na qualidade da auditoria realizada. Entre estas características, pode-se citar, o tamanho da firma de auditoria, o tempo de 
relacionamento entre a firma de auditoria e o cliente e a especialização da firma de auditoria. Diversas pesquisas buscam relacionar a qualidade da auditoria com o desempenho econômico-financeiro das empresas auditadas (RUDDOCK; TAYLOR; TAYLOR, 2006), sistema de governança corporativa (FURUTA, 2010), nível de gerenciamento de resultados (BECKER et al, 1998; MARTINEZ, 2001; PIOT, 2005), conservadorismo da informação contábil (PAULO, 2012).

Entretanto, poucas pesquisas se dedicam a analisar a influência das diversas características da auditoria sobre o conjunto de atributos da informação contábil. Esperase que esta pesquisa contribua para um melhor entendimento da relação entre a auditoria e qualidade da informação contábil no mercado de capitais, de forma a auxiliar os investidores e reguladores deste ambiente.

A relevância deste estudo pode ser dividida em dois grupos:

- Relevância prática: contribuir com o melhor entendimento acerca das características que afetam a qualidade da auditoria e a sua influência na qualidade da informação contábil, na qual as companhias, de maneira geral, podem verificar a relação entre auditoria e informação contábil, afim de melhorar a qualidade das informações reportadas aos agentes externos a empresa.

- Relevância teórica: contribuir com a literatura previamente existente, principalmente no que concerne na discussão das características que afetam na qualidade da auditoria e os atributos da qualidade das informações contábeis. 


\section{REFERENCIAL TEÓRICO}

\subsection{AUDITORIA INDEPENDENTE E SUA IMPORTÂNCIA}

O Report of the Committee in Basic Auditing Concepts of the American Accounting Association (Relatório do Comitê em Conceitos Básicos de Auditoria da Associação Americana de Contabilidade) define Auditoria como:

Um processo sistemático de obtenção e avaliação objetiva de evidências sobre afirmações a respeito de ações e eventos econômicos, para aquilatação do grau de correspondência entre as afirmações e critérios estabelecidos, e de comunicação dos resultados a usuários interessados (BOYNTON; JOHNSON; KELL, 2002, p. 30-31).

Boynton, Johnson e Kell (2002), tratando especificamente da auditoria das demonstrações contábeis, destacam que esta envolve obtenção e avaliação de evidências a respeito das demonstrações contábeis da entidade, para a elaboração de um parecer, se sua apresentação for adequada, conforme os Princípios Contábeis Geralmente Aceitos (PCGAs).

Segundo Needles Jr., Ramamoorti e Shelton (2002) a auditoria contábil tem como principal função garantir a fidedignidade dos relatórios financeiros apresentados aos usuários das informações contábeis, uma vez que a sociedade atribui a auditoria uma forma de se assegurar quanto à veracidade das informações contábeis reportadas pelas organizações.

Para Santos et al. (2009) o objetivo final da auditoria é fornecer à administração, ao fisco, aos proprietários e financiadores do patrimônio a convicção de que as demonstrações contábeis refletem a situação do patrimônio em determinada data e suas variações em certo período.

Conforme exposto anteriormente, a auditoria aparece como importante ferramenta aos usuários dos relatórios contábeis, a qual é responsável por uma maior confiabilidade dos relatórios financeiros evidenciados pela companhia.

Neste sentido, a Teoria da Agência desenvolvida por Jensen e Meckling (1976), no âmbito do risco moral, auxilia a esclarecer o porquê da existência da assimetria informacional entre empresas e outros agentes do mercado no sentido em que busca explicar o motivo pelo qual as demonstrações financeiras devem ser auditadas.

Boynton, Johnson e Kell (2002) abordam que a auditoria de empresas começou com a legislação britânica promulgada durante a Revolução Industrial, em meados do século XIX. Nos Estados Unidos da América, apenas após a quebra da bolsa de Nova Iorque em 
1929, foi que a classe de auditores passou a ter maior importância dentro do contexto empresarial. Isto se deve ao fato de que foi instituída a obrigatoriedade da auditoria contábil nas empresas que comercializavam ações no mercado de capitais.

Em 1934, surgiu a SEC (Securities and Exchange Commission), órgão que passou a ser o regulador do mercado de capitais norteamericano, atribuindo ainda mais importância a auditoria independente. Enquanto que, em 1977, foi criado o IFAC (International Federation of Accountants), que atualmente é o responsável pela elaboração de normas internacionais de auditoria, bem como outras atividades.

Enquanto que no Brasil, a auditoria ganhou propulsão com a criação do Banco Central do Brasil (BACEN), a elaboração da lei nº 6.404/1976, conhecida com a Lei das Sociedades Anônimas e o surgimento da Comissão de Valores Mobiliários (CVM), mediante a Lei ${ }^{\circ}$ 6.385/1976.

O artigo 26 da Lei $\mathrm{n}^{\circ}$ 6.385/1976, tratando da auditoria das demonstrações contábeis das companhias abertas, traz que:

\footnotetext{
Somente as empresas de auditoria contábil ou auditores contábeis independentes, registrados na Comissão de Valores Mobiliários poderão auditar, para os efeitos desta Lei, as demonstrações financeiras de companhias abertas e das instituições, sociedades ou empresas que integram o sistema de distribuição e intermediação de valores mobiliários.
}

Verifica-se que, desta forma, a CVM tenta garantir um melhor acompanhamento das atividades realizadas pelos auditores.

Outro marco se refere ao contexto dos escândalos corporativos, que impulsionaram a criação da Lei Sarbanes-Oxley, no ano de 2002. A SOX, como é popularmente conhecida, trouxe diversas alterações que afetaram todos os agentes envolvidos no mercado (administradores, auditores, advogados e analistas), conforme exposto por Silva e Robles Junior (2008). Os autores abordam que, dentre estas mudanças, as que impactaram diretamente a auditoria independente foram: a) criação de órgão fiscalizador (Public Company Accounting Oversight Board - PCAOB); b) novas regras de independência; e c) renovação das normas de auditoria.

Mediante o exposto, verifica-se a importância da auditoria e toda preocupação dos órgãos reguladores do mercado em relação a sua atividade. Porém, esta preocupação não é particularmente em relação a auditoria das companhias que operam no mercado de capitais, mas também por parte das agências reguladoras de determinados setores de atividades, como, por exemplo, a Agência Nacional de Saúde Suplementar (ANS), a 
Agência Nacional de Telecomunicações (Anatel) e a Superintendência de Seguros Privados (SUSEP).

\subsection{QUALIDADE DA AUDITORIA INDEPENDENTE}

A qualidade dos serviços de auditoria é definida por DeAngelo (1981) como a probabilidade de determinado auditor descobrir uma brecha no sistema de contabilidade do cliente e denunciar tal brecha.

Segundo Gul, Kim e Qiu (2010), auditoria considerada de "alta qualidade" pode 'forçar' seus clientes a divulgar de forma mais detalhada, oportuna e com melhor qualidade as informações contábeis da empresa, contribuindo para maior proteção aos acionistas minoritários. Com as informações mais detalhadas e de melhor qualidade, espera-se que as decisões a serem tomadas pelos investidores ocorram de forma mais adequada, afetando assim a precificação das ações da companhia, conforme observado na pesquisa de Lima et al. (2012).

Para DeFond e Zhang (2014) "a qualidade da auditoria melhora a qualidade do relatório financeiro, aumentando a credibilidade destes relatórios. Mediante o exposto, verifica-se que a auditoria é um componente primordial para aumento da qualidade dos relatórios financeiros reportados pelas companhias"1.

Defond e Zhang (2014) ainda explicam a oferta de qualidade de auditoria é uma função com base em dois pontos: a independência e competência do auditor, onde a independência surge a partir da reputação e incentivos litigiosos, e a competência referese à capacidade de fornecer alta qualidade de auditoria.

De acordo com Francis (2004) a qualidade da auditoria pode ser conceituado como um continuum teórico que pode variar de muito baixa à altíssima qualidade de auditoria e que falhas de auditoria ocorrem na extremidade inferior da qualidade. $\mathrm{O}$ mesmo autor traz que a falha de auditoria acontece em duas circunstâncias: quando os princípios contábeis geralmente aceitos (PCGAs) não são aplicados pelo auditor ou quando o auditor deixa de emitir um relatório de auditoria modificado ou qualificado nas cirscuntâncias adequadas. Em ambos os casos, as demonstrações financeiras são potencialmente enganosas para os usuários.

Como se pode observar, a qualidade da auditoria independente é mensurada mediante algumas características qualitativas da auditoria. Neste estudo foram utilizadas

\footnotetext{
1 Tradução livre de: "Theory suggests that the supply of audit quality is a function of the auditor's independence and competency, where independence arises from reputation and litigation incentives, and competency refers to the ability to deliver high audit quality".
} 
as seguintes características da auditoria: tamanho da firma de auditoria; período de relacionamento entre a firma de auditoria e o cliente; serviços de não auditoria; presença do comitê de auditoria; tempo de emissão do relatório.

\subsubsection{Tamanho da Firma de auditoria}

Estudos tem se concentrado em analisar o efeito do tamanho da empresa de auditoria como característica qualitativa da qualidade da auditoria (DEFOND; SUBRAMANYAM, 1998; BAUWHEDE; WILLEKENS; GAEREMYNCK, 2003; JEONG; RHO, 2004; CUPERTINO; MARTINEZ, 2008; IATRIDIS, 2011).

A literatura existente aborda o tamanho da firma de auditoria como proxy para qualidade da auditoria mediante duas justificativas. Primeiramente, traz o quesito econômico, onde as maiores empresas de auditoria apresentam maior independência econômica e, posteriormente, pela qualificação destas empresas, visto que, teoricamente, seus funcionários serão mais bem treinados do que as firmas menores de auditoria.

Em relação a este primeiro quesito, Fargher, Taylor e Simon (2001) afirmam que as maiores empresas internacionais de auditoria independente, conhecidas como Big Four, possuem maior reputação em seu ramo, sugerindo uma maior independência econômica. Esta afirmação corrobora com DeAngelo (1981), onde este argumenta que o tamanho da firma de auditoria é positivamente relacionada com a qualidade da auditoria, pois firmas maiores de auditoria possuem maior portfólio de clientes, tornando-as menos dependente de determinado cliente. Iatridis (2011) encontrou em sua pesquisa que as empresas auditadas por Big Four apresentam maior qualidade da evidenciação contábil.

O tamanho da firma de auditoria como proxy da qualidade da auditoria está baseada no fato de que as grandes firmas de auditoria (Big Four) têm uma reputação a zelar, uma vez que possuem mais clientes que as demais firmas, e elas apresentam menor dependência econômica de seus clientes, visto que conseguem captar um grande número de clientes para prestar os serviços de auditoria.

Clarkson e Simunic (1994), baseados na teoria da sinalização (SPENCE, 1973), afirmam que as empresas com emissão de novas ações no mercado acionário tendem a contratar uma grande firma de auditoria, com o intuito de sinalizar ao mercado um menor nível de risco associado a companhia emissora de tais ações. Com isto, admite-se que o tamanho da firma de auditoria pode afetar a percepção dos agentes envolvidos no mercado, afetando, assim a precificação das ações das companhias.

2.2.2. Período de relacionamento entre a firma de auditoria e o cliente 
Com o intuito de minimizar a dependência do auditor externo, surgiu o mecanismo de rodízio das auditorias independentes. Paulo (2012) fala que a prestação de serviços de auditoria para uma mesma entidade, por um longo período de tempo, pode prejudicar a qualidade do serviço; assim, o rodízio dos auditores reduzirá os conflitos de interesses causados pela relação longínqua entre cliente e auditor.

Ou seja, mais uma qualidade da auditoria que sofre influência do nível de dependência entre a firma da auditoria e o cliente, uma vez que o maior tempo de relacionamento entre estas partes acarretará numa maior familiariadade, podendo trazer prejuízos a qualidade dos serviços de auditoria prestados.

Porém, o rodízio de auditoria acarretará na perda de maior especialização por parte da auditoria para com o cliente, conforme abordado por Ghosh e Moon (2005), entretanto esta especialização não será afetada caso a firma de auditoria continue prestando serviços de auditoria em determinado ramo.

A instrução normativa CVM n ${ }^{\circ}$ 308/1999, que dispõe sobre o registro e o exercício da atividade de auditoria independente, traz que o auditor independente, seja este pessoa física ou jurídica, não pode prestar serviços para o mesmo cliente por um prazo superior a cinco anos consecutivos e exigi-se um intervalo mínimo de três anos para a recontratação do auditor. A justificativa dada para a elaboração de tal instrução, se dá pela possibilidade de comprometer a qualidade dos serviços prestados pelo auditor.

\subsubsection{Serviços não relacionados a auditoria}

Francis e Ke (2006) afirmam que a independência da auditoria torna-se cada vez mais fraca conforme as receitas provenientes de outros serviços não relacionados com a auditoria são mais evidentes no faturamento da firma de auditoria. Chahine e Filatotchev (2011) trazem que os valores pagos por serviços de não auditoria são geralmente considerados como uma ameaça à independência e objetividade do auditor, sendo esperado que ocasione reação negativa pelos investidores da empresa.

Mediante o exposto, verifica-se que os montantes pagos para prestação de outros serviços pelas firmas de auditoria podem ocasionar numa maior dependência desta firma em relação ao cliente, uma vez que seu faturamento aumentou mediante a contratação destes serviços.

Os serviços não relacionados a auditoria ofertados pelas firmas de auditoria variam conforme a firma, porém, principalmente as Big 4, oferecem outros serviços, onde pode- 
se citar como exemplos: consultoria tributária, emissão de ações, outsourcing, financial advisory, entre outros.

Estudos foram realizados utilizando esta característica como proxy para a qualidade da auditoria (FRANCIS; KEN, 2006; RUDDOCK; TAYLOR; TAYLOR, 2006; PAULO, 2012), demonstrando a relevância desta variável no estudo do campo da auditoria.

\subsubsection{Presença do Comitê de Auditoria}

A presença do comitê de auditoria na firma auditada, parte do pressuposto de que setor da companhia é o responsável por indicar, estabelecer a remuneração e supervisionar o auditor independente, sendo independente da administração da companhia, fazendo com que esta própria administração seja menos propensa a ter comportamentos litigiosos em seu relacionamento com os auditores independentes.

Koch, Weber e Wüstemann (2011) apresentam que, caso a contratação ocorra pela administração da organização, os auditores independentes são mais maleáveis em aceitar determinados métodos contábeis preferidos pela gestão da companhia. Percebe-se que esta característica qualitativa da auditoria também apresenta maior ou menor independência da mesma, dependendo de qual setor da empresa será responsável por sua contratação, bem como a sua supervisão.

Alguns estudos utilizam o comitê de auditoria como proxy para a qualidade da auditoria (KLEIN, 2002; MOORE et. al, 2006; RAINSBURY; BRADBURY; CAHAN, 2009; KOCH; WEBER; WÜSTEMANN, 2011), podendo ser abordado sobre a importância desta característica nos estudos acerca da qualidade da auditoria.

\subsubsection{Tempo de Emissão do Relatório de Auditoria}

$\mathrm{Ng}$ e Tai (1994) definem o tempo de emissão do relatório de auditoria como o período entre o final do ano auditado e a data do relatório emitido pela firma de auditoria.

Mande e Son (2011) abordam que "um longo atraso de auditoria muitas vezes ocorre devido a problemas na auditoria, as divergências entre o auditor e o cliente sobre questões contábeis e/ou uma deterioração geral na qualidade da interação entre auditor/cliente",2.

Pode-se considerar que a velocidade de emissão do relatório de auditoria pode sinalizar algum atributo da qualidade sobre as informações contábeis reportadas pela

\footnotetext{
2 Tradução livre de: "A lengthy audit delay often occurs due to problems in the audit, disagreements between the auditor and client on accounting issues, and/or a general deterioration in the quality of auditorclient interaction."
} 
empresa (PAULO, 2012). Sendo assim, é possível perceber que existe a possibilidade das companhias solicitarem a emissão do relatório de auditoria com maior brevidade, visto que isto poderá acarretar numa percepção por partes dos usuários de que a empresa possui alta qualidade de auditoria.

\subsection{QUALIDADE DA INFORMAÇÃO CONTÁBIL}

A informação é algo que move o mundo atualmente, a cada instante as tecnologias da informação evoluem e trazem uma gama de novidades, os usuários das mais diversas informações anseiam que estas apresentem características como compreensibilidade e utilidade (relevância), características presentes no Framework desenvolvido pelo IASB (International Accounting Standards Board). A cada nova informação útil apresentada, tem-se uma nova perspectiva acerca do objeto de análise, ora ratificando a decisão anteriormente formada, ora alterando o posicionamento previamente definido.

Conforme exposto por Yamamoto e Salotti (2006) a informação contábil relevante pode ser considerada como aquela em que é alterado o estado da arte do conhecimento do usuário em relação à companhia, pois, mediante sua interpretação, este usuário a utiliza em seu processo de tomada de decisão.

Segundo Dechow, Ge e Schrand (2010), não existe uma definição adequada para a qualidade da informação a ser considerada na tomada de decisões em todos os contextos. Os autores defendem que a qualidade da informação contábil deverá levar em consideração o contexto específico na qual está inclusa e que esta qualidade pode ser considerada como um conjunto de diversos atributos, como gerenciamento de resultados contábeis, conservadorismo, qualidade na mensuração dos accruals, persistência, transparência, relação dos números contábeis com o desempenho dos preços das ações ou do valor de mercado da firma, nível de disclosure.

O presente trabalho terá como objetivo analisar trêso qualidades da informação contábil, são elas: conservadorismo condicional, qualidade na mensuração dos accruals e o value relevance.

Tratando da relação entre qualidade da auditoria e qualidade da informação contábil, Francis (2004) ao sumarizar os conhecimentos acerca da qualidade da auditoria, afirma que esta é positivamente relacionada com a qualidade da informação contábil (qualidade dos lucros), ou seja, quanto melhor a qualidade da auditoria, melhor será a qualidade da informação reportada pelas empresas.

\subsubsection{Conservadorismo}


A primeira qualidade da informação contábil analisada foi o conservadorismo contábil. Esta qualidade da informação contábil é defendida por Watts (2003), uma vez que assegura que não sejam reportadas informações excessivamente otimistas para os usuários destas informações. Porém, o conservadorismo contábil pode ser dividido em dois grupos: incondicional e condicional. O primeiro, o conservadorismo incondicional, segundo Coelho (2007), decorre de regra de que entre duas alternativas de mensuracao e reconhecimento de eventos, igualmente validas, deve-se escolher aquela que resulte na menor avaliacao do patrimonio dos proprietarios; seu proposito é o da prudencia e está diretamento relacionado ao grau de incerteza sobre os efeitos derivados de transações iniciadas.

Coelho (2007) ainda conceitua o conservadorismo condicional, utilizado no presente estudo, como aquele que se refere à possibilidade de antecipar o reconhecimento contábil das perdas econômicas (ainda não realizadas) à luz de estimativas realizadas pela gerência com base em eventos atuais de cunho negativo, frisando o reconhecimento de tais fatos gera uma assimetria informacional, privilegiando os indícios de resultados negativos. Esta conceituação corrobora com o exposto por Basu (1997), onde o mesmo expõem o conservadorismo condicional como o resultado que reflete as más notícias de forma mais rápida do que as boas notícias.

O reconhecimento oportuno das perdas fornece informações mais precisas anteriores à precificação de contratos de dívida e faz com que sejam percebidos mais rapidamente descumprimentos de acordos de financiamento tais como restrições à contratação de mais dívidas ou ao pagamento de dividendos e descapitalização da empresa, fatores que ocorrem após a concessão de crédito, sendo esta qualidade considerada importante para a mensuração dos elementos do patrimônio, em razão de salvaguardar o interesse dos credores nos ativos líquidos da empresa (BALL; SHIVAKUMAR, 2005).

O conservadorismo implica decisões sobre o momento do reconhecimento oportuno dos ganhos e das perdas e, consequentemente, influencia a escolha contábil. Porém, como outras características da informação contábil, o conservadorismo sofre influência do ambiente institucional e organizacional das empresas (PAULO, 2012).

Watts (2003) explica que os relatórios contábeis apresentam problemas envolvendo risco moral em razão de os mesmos mensurarem o desempenho da administração e afetar as decisões de investimento e o bem estar dos administradores. As consequências da apresentação de resultados aquém dos esperados fornecem subsídios para que os 
administradores introduzam algum viés na mensuração dos resultados os quais devem ser informados aos investidores, sendo o conservadorismo uma maneira de se reprimir o comportamento oportuno dos administradores e balancear qualquer viés otimista introduzido por estes na mensuração dos elementos das demonstrações contábeis. Com isto, verifica-se que o mesmo pode ser considerado um eficiente mecanismo de redução de litígios, onde restringe os pagamentos oportunistas para administradores e acionistas, e nesse cenário a auditoria se torna uma importante ferramento no auxilio a detecção de possíveis comportamentos oportunisticas por parte dos administradores.

O estudo que buscou verificar a influência de determinada proxy para qualidade da auditoria no conservadorismo foi o de Krishnan (2004), onde se verificou que os lucros auditados por firmas de auditoria com maior nível de especialização são mais conservadoras, conforme o modelo de conservadorismo proposto por Basu (1997).

\subsubsection{Qualidade na mensuração dos accruals}

Dechow e Dichev (2002) afirmam que os accruals são frequentemente baseados em pressupostos e em estimativas que, caso incorretas, devem sofrer correções em futuros accruals, consequentemente, tais ajustes irão afetar os resultados futuros da companhia. Com isto, erros na mensuração dos accruals afetam negativamente o conteúdo informacional dos accruals sobre os resultados futuros e fluxos de caixa futuros. Barth, Cram e Nelson (2001) separaram o modelo dos accruals e concluiram que os componentes de caixa em conjunto com os componentes dos accruals que estão no resultado, possuem maior capicidade de previsão de fluxos de caixa futuros do que o próprio resultado como um todo.

Nada de errado existe no registro de accruals; na verdade, o intuito é mensurar o lucro no seu sentido econômico, aquele que representa acréscimo efetivo na riqueza patrimonial da unidade econômica, independente da movimentação financeira. $O$ problema está no fato de o gestor discricionariamente aumentar ou diminuir esses accruals com o objetivo de influenciar o lucro (MARTINEZ, 2008).

Defond e Jiambalvo (1994) inferem ainda que administradores têm estímulos para aumentar os lucros por meio de accruals discricionários positivos como forma de conseguir menores taxas de juros para empréstimos e diminuir o custo de capital. Nesse sentido, o auditor deve realizar seu trabalho verificando possível atitude agressiva por parte da gestão da empresa, como forma de aumentar seus lucros, como abordado anteriormente. 
Estudos realizados encontraram que existe relação negativa entre os accruals discricionários e o tempo de relacionamento entre o cliente e a firma de auditoria no mercado norte americano (MYERS; MYERS; OMER, 2003) e no mercado tailandês (CHEN; LIN; LIN, 2008).

\subsubsection{Value Relevance}

De acordo com Iudícibus e Lopes (2004), o estudo do papel da contabilidade como responsável por fornecer informações para o mercado de capitais é de extrema importância para a avaliação da eficiência da informação contábil no atendimento de alguns de seus mais importantes usuários. Com isto, verifica-se a importância da informação reportada para que sejam tomadas decisões acerca desta informação, impactando, possivelmente, na precificação das ações. Barth, Beaver e Landsman (2001) trazem que, se a informação contábil tem impacto no preço das ações, significa que esta informação é relevante para o mercado de capitais, pelo menos a certo nível de significância.

Lee e Lee (2013) abordam que o value relevance, combinando os efeitos da relevância e da confiabilidade, tem sido um dos principais problemas nas pesquisas em mercado de capitais baseadas em contabilidade pelas últimas duas décadas.

Ohlson (1995) define relevância como a relação entre os números contábeis e o retorno de mercado das ações da companhia. A auditoria pode influenciar no preço das ações, uma vez que, serve como forma de sinalizar menor nível de risco específico da empresa, conforme defendido por Clarkson e Simunic (1994), corroborando com Palmrose (1986), onde o mesmo traz que, partindo com base na Teoria da Sinalização, o IPO (Initial Public Offering) das empresas podem utilizar serviços de auditoria externos para resolver o problema de assimetria da informação e conflitos de agência entre os gestores e investidores do mercado de capitais.

Segundo Lee e Lee (2013), a "melhor qualidade de auditoria pode melhorar a relevância e a confiabilidade das demonstrações contábeis dos clientes e, consequentemente, melhorar a relevância das informações financeiras"3. Desta forma, a auditoria está cumprindo com o seu principal objetivo, atribuindo maior confiabilidade e, consequentemente, reduzindo os riscos acerca da companhia auditada.

\footnotetext{
${ }^{3}$ Tradução livre de: "Higher audit quality may enhance the relevance and reliability of clients' financial statements, and hence improve the value relevance of financial statement information."
} 


\subsection{PESQUISAS EMPÍRICAS SOBRE OS TEMAS PESQUISADOS}

Para aprofundamento e panorama acerca do tema pesquisado, realizou-se levantamento de pesquisas empíricas realizadas sobre o tema proposto neste estudo, qualidade da auditoria. Tal levantamento ocorreu mediante a utilização do site Web Of Science, mantida pela empresa Thomson Reuters, onde tal site é uma base de referências bibliográficas, abrangindo, aproximadamente, 12.000 periódicos.

O levantamento realizado atráves do termo "audit quality” no site Web Of Science, onde obteve-se o retorno de 323 artigos nos últimos 20 anos, contidos nas seguintes categorias do site: Business Economics, Management, Finance e Economics. Mediante a figura 1 observa-se a quantidade de artigos indexados pelos periódicos contidos na base de dados do WebOfScience e a quantidade de citações de tais artigos ao longo do últimos vinte anos. Verifica-se que o ano de 2011 apresentou o maior número de pesquisas sobre o tema "audit quality", totalizando 29 publicações. Outro ponto importante de observar é que, após o ano de 2011, a quantidade de publicações ao longo dos anos subsequentes manteve-se acima de 20 pesquisas publicadas por ano.

Figura 1 - Itens publicados sobre "Audit Quality" nos últimos 20 anos
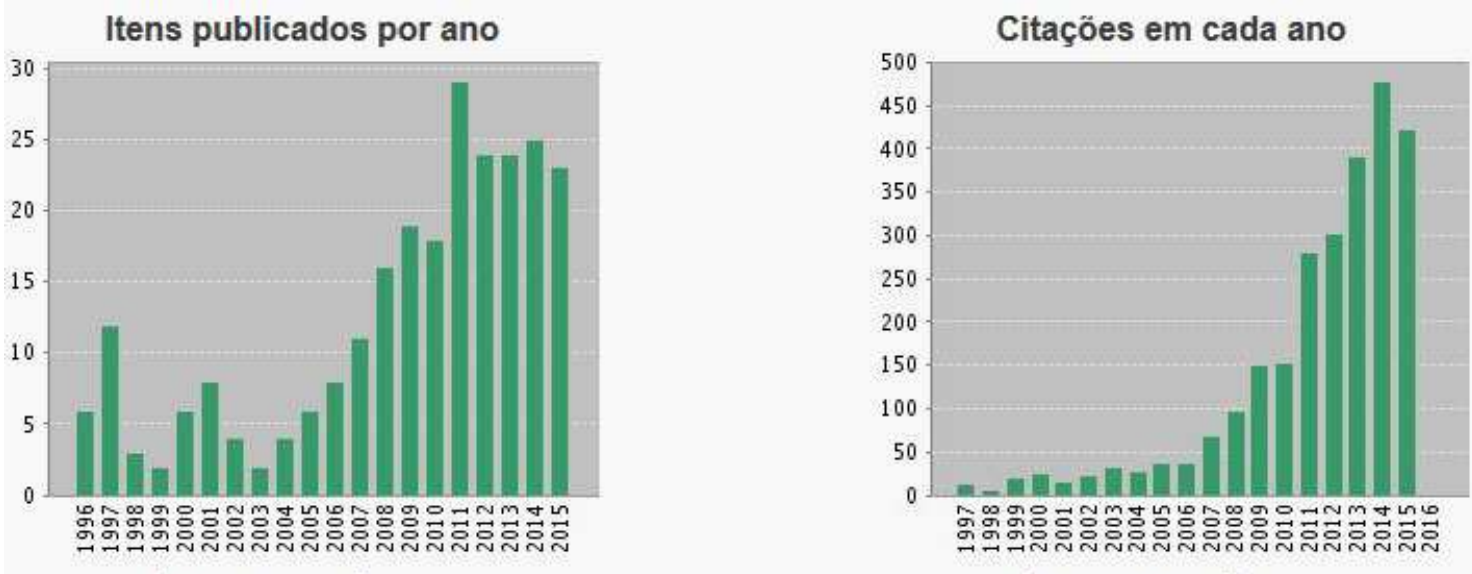

Os últimos 20 anos são exibidos.

Os últimos 20 anos são exibidos.

Fonte: WebOfScience

O artigo com o maior número de citações, totalizando 149 citações e com uma média de 5,32 citações por ano, foi o estudo desenvolvido por Zoe-Vonna Palmrose no ano de 1988 intitulado An Analysis of Auditor Litigation and Audit Service Quality, publicado na Accounting Review. Tal estudo teve como objetivo comparar atividades de litígios entre as maiores firmas de auditoria independente dos Estados Unidos, onde se verificou a ocorrência de ações contra os auditores, indicando falha de auditoria (atividades de litigios). A autora inferiu que as maiores firmas de auditoria, na época conhecidas como Big-8, apresentam menos ocorrências de litígios que as menores firmas 
de auditoria, sendo consistente com a literatura, uma vez que as firmas maiores de auditoria, teoricamente, apresentam uma qualidade de auditoria diferenciada.

A maior média de citações foi do artigo Ownership concentration, foreign shareholding, audit quality, and stock price synchronicity: Evidence from China, publicado no Journal of Financial Economics no ano de 2010, com uma média de 10,5 citações por ano. O estudo analisou os efeitos da maior concentração de propriedade dos acionistas, investidores estrangeiros e qualidade da auditoria sobre a quantidade de informações especificas da empresa incorporadas no preço das ações. Os resultados relacionados a qualidade da auditoria (nesse estudo utilizou-se o tamanho da firma, se a mesma era Big 4 ou não) sugerem que as Big 4 desempenham um papel importante na divulgação de informações especificas, atribuindo maior credibilidade aos relatórios financeiras da empresa. 


\section{PROCEDIMENTOS METODOLÓGICOS}

\subsection{TIPOLOGIA DA PESQUISA}

Esta pesquisa utiliza a tipologia elaborada por Beuren (2006), que classifica a pesquisa quanto aos objetivos, aos procedimentos e à abordagem de pesquisa. Quanto aos objetivos, este estudo pode ser classificado como descritivo, pois o estudo buscou “[...] observar, registrar, analisar e correlacionar fatos e fenômenos (variáveis) sem manipulálos." (CERVO; BERVIAN, 2002, p.66).

Quanto aos procedimentos é classificada como uma pesquisa bibliográfica e documental. Gil (2008) discute a semelhança destes dois tipos de pesquisa, onde a primeira tem como base contribuições de diversos autores sobre determinado tema, sendo utilizado, para este estudo, principalmente, livros e artigos científicos. Enquanto que o segundo tipo de pesquisa, a pesquisa documental, utiliza-se de material que não receberam tratamento analítico.

Por fim, quanto à abordagem de pesquisa, o estudo também classificou-se como uma pesquisa quantitativa, a qual Richardson (1999) caracteriza esta abordagem de pesquisa pelo emprego da quantificação tanto para a coleta de informações, como para o tratamento de tais informações, utilizando técnicas estatísticas, desde as mais simples até as mais complexas. O quadro 3, ao final do presente tópico, procedimentos metodológicos, sumariza as características da metodologia do presente estudo.

\subsection{PLANO AMOSTRAL E PROCEDIMENTOS PARA A COLETA DE DADOS}

A população deste estudo foi formada pelas companhias abertas brasileiras, onde a escolha deste país deve-se a disponibilidade dos dados no software Thomson Reuters Eikon $^{\circledR}$, bem como para a melhor compreensão da influência de características da auditoria independente na qualidade da informaçãoo contábil.

As informações necessárias a esta pesquisa foram coletadas mediante a base de dados da BM\&FBovespa, do software Thomson Reuters ${ }^{\circledR}$ Eikon e das demonstrações financeiras publicadas pelas companhias, compreendendo o período de 2005 a 2014 . A escolha do período a ser analisado se deve ao fato da representatividade do mesmo, visto que contempla uma análise de 10 anos.

Com o intuito de evitar algum viés na amostra e problemas de especificação na estimação dos modelos utilizados, foram excluídas desta pesquisa:

a) As companhias com dados ausentes necessários a este estudo; 
b) As companhias que atuam na atividade financeira, tais como: bancos, seguradoras, previdência privada ou particular, administração de empresas e empreendimentos ou que tenham receitas operacionais exclusivamente oriundas de participações societárias, pois:

i. Os procedimentos de mensuração contábil adotados são diferentes substancialmente das demais companhias e, provavelmente, não são capturados adequadamente pelos modelos analisados; e

ii. A alavancagem comum a este tipo de empresa é vista como dificuldade financeira para as demais companhias (FAMA; FRENCH, 1992).

c) As companhias com passivo a descoberto também foram excluídas, pois utilizouse de índices baseados no patrimônio líquido.

O quadro 1 abaixo mostra a quantidade de observações iniciais, a quantidade de observações com dados necessários para realizar as análises (amostra final) e o percentual de aceitação da amostra em relação a população. Observa-se que a amostra final da qualidade da mensuração dos accruals foi inferior as demais, sendo justificada pelo fato de que é necessário dados de período posterior, não podendo analisar o ano de 2014, uma vez que os dados de 2015 ainda não estão disponíveis para análise.

Quadro 1 - Detalhamento da amostra utilizada na pesquisa

\begin{tabular}{|c|c|c|c|}
\hline Qualidade da Informação Contábil & População $^{\mathbf{i}}$ & Amostra Finali $^{\text {ii }}$ & Amostra Aceita (\%) $^{\text {Conservadorismo }}$ \\
\hline Qualidade da Mensuração dos Accruals & 4.351 & 1.310 & 30,11 \\
\hline Value Relevance & 4.351 & 982 & 22,59 \\
\hline
\end{tabular}

Fonte: Própria

No quadro 2 abaixo, contem a quantidade de companhias analisadas por ano segregadas pelos atributos da qualidade da informação contábil analisados. Conforme exposto anteriormente, não foi realizado a análise da qualidade na mensuração dos accruals no ano de 2014, uma vez que era necessário os dados de 2015, ainda não disponível.

\footnotetext{
i A população deste estudo é composta por todas as empresas com dados disponíveis para o período analisado no software Thomson Reuters Eikon, inclusive as entidades financeiras e com passivo a descoberto.

ii A amostra final é composta apenas pelas companhias que apresentaram os dados necessários (financeiros e de auditoria) para mensuração dos três atributos da qualidade da informação contábil analisados pelo presente estudo (conservadorismo, qualidade na mensuração dos accruals e value relevance).
} 
Quadro 2 - Detalhamento da amostra por ano

\begin{tabular}{|c|c|c|c|}
\hline Ano & Conservadorismo & $\begin{array}{c}\text { Qualidade na } \\
\text { Mensuração dos } \\
\text { Accruals }\end{array}$ & Value Relevance \\
\hline 2005 & 43 & 11 & 32 \\
\hline 2006 & 44 & 15 & 31 \\
\hline 2007 & 77 & 39 & 57 \\
\hline 2008 & 112 & 97 & 104 \\
\hline 2009 & 128 & 115 & 114 \\
\hline 2010 & 162 & 159 & 150 \\
\hline 2011 & 179 & 179 & 160 \\
\hline 2012 & 181 & 184 & 160 \\
\hline 2013 & 189 & 183 & 175 \\
\hline 2014 & 195 & - & 186 \\
\hline TOTAL & $\mathbf{1 . 3 1 0}$ & $\mathbf{9 8 2}$ & $\mathbf{1 . 1 6 9}$ \\
\hline
\end{tabular}

Fonte: Própria

Durante o processo de estimação, como ocorre frequentemente em qualquer processo do tipo, foram detectados a presença de outliers. Wooldridge (2003) explica que tais observações podem trazer informações relevantes, aumentando a variabilidade das variáveis explicativas e, portanto, reduzindo os erros-padrão. Com isto, visando a não exclusão dos outliers, foram excluídas das amostras dados numéricos com 4 desviospadrão acima e abaixo da média, sendo tal procedimento consistente com o de outras pesquisas (SUBRAMANYAM, 1996; PAULO, CAVALCANTE; MELO, 2012). Ressalva-se que os Quadros 1 e 2 expostos anteriormente apresentam os dados sem os outliers.

\subsection{DEFINIÇÃO DOS MODELOS EMPREGADOS E VARIÁVEIS}

\subsubsection{Modelo de mensuração do nível de conservadorismo}

Para mensuração do grau de conservadorismo contábil das companhias analisadas, foi utilizado o modelo proposto por Ball e Shivakumar (2005), conforme equação 1 abaixo (Modelo Original):

$$
\Delta \mathrm{NI}_{\mathrm{it}}=\beta_{0}+\beta_{1} \mathrm{D} \Delta \mathrm{NI}_{\mathrm{it}-1}+\beta_{2} \Delta \mathrm{NI}_{\mathrm{it}-1}+\beta_{3} \Delta \mathrm{NI}_{\mathrm{it}-1} * \mathrm{D} \Delta \mathrm{NI}_{\mathrm{it}-1}+\beta_{4} \mathrm{QA}_{\mathrm{it}}
$$

em que:

$\Delta \mathrm{NI}_{\mathrm{it}}=$ variação no lucro líquido contábil da empresa $i$ do ano $t-1$ para o ano $t$;

$\mathrm{D} \Delta \mathrm{NI}_{\mathrm{it}-1}=$ variável dummy para indicar se existe variação negativa no lucro líquido contábil da empresa $i$ do ano $t$ - 1 para o ano $t\left(\Delta \mathrm{NI}_{\mathrm{it}}\right)$, assumindo valor 1 se $\Delta N I_{i t}<0$, e 0 nos demais casos;

$\Delta \mathrm{NI}_{\mathrm{it}-1}=$ variação no lucro líquido contábil da empresa $i$ do ano $t-2$ para o ano $t-1$; 
Para captação da influência de características da auditoria, foi utilizado uma adaptação do modelo original do Ball e Shivakumar(2005), conforme visto em outros trabalhos (PAULO, 2012; BEUREN; THEISS; SANT'ANA, 2013; DANTAS, PAULO; MEDEIROS, 2013). Segue equação 2 abaixo (Modelo Adaptado):

$$
\begin{aligned}
& \Delta \mathrm{NI}_{\mathrm{it}}=\beta_{0}+\beta_{1} \mathrm{D} \Delta \mathrm{NI}_{\mathrm{it}-1}+\beta_{2} \Delta \mathrm{NI}_{\mathrm{it}-1}+\beta_{3} \Delta \mathrm{NI}_{\mathrm{it}-1} * \mathrm{D} \Delta \mathrm{NI}_{\mathrm{it}-1}+\beta_{4} \mathrm{QA}_{\mathrm{it}}+\beta_{5} \mathrm{QA}_{\mathrm{it}} * \\
& \mathrm{D} \Delta \mathrm{NI}_{\mathrm{it}-1}+\beta_{6} \mathrm{QA}_{\mathrm{it}} * \Delta \mathrm{NI}_{\mathrm{it}-1}+\beta_{7} \mathrm{QA}_{\mathrm{it}} * \Delta \mathrm{NI}_{\mathrm{it}-1} * \mathrm{D} \Delta \mathrm{NI}_{\mathrm{it}-1}+\varepsilon_{\mathrm{it}}
\end{aligned}
$$

em que:

$\Delta \mathrm{NI}_{\mathrm{it}}=$ variação no lucro líquido contábil da empresa $i$ do ano $t-1$ para o ano $t$;

$\mathrm{D} \Delta \mathrm{NI}_{\mathrm{it}-1}=$ variável dummy para indicar se existe variação negativa no lucro líquido contábil da empresa $i$ do ano $t-1$ para o ano $t\left(\Delta \mathrm{NI}_{\mathrm{it}}\right)$, assumindo valor 1 se $\Delta N I_{i t}<0$, e 0 nos demais casos;

$\Delta \mathrm{NI}_{\mathrm{it}-1}=$ variação no lucro líquido contábil da empresa $i$ do ano $t-2$ para o ano $t-1$;

$\mathrm{QA}_{\mathrm{it}}=$ proxy para qualidade da auditoria da empresa $i$ do ano $t$;

$\varepsilon_{\text {it }}=$ erro da regressão.

Ball e Shivakumar (2005) trazem que, para que os resultados positivos se tornem componente persistente do lucro contábil das companhias, o coeficiente $\beta_{2}$ deve ser igual a zero, pois o reconhecimento dos ganhos é diferido até o momento em que os seus fluxos de caixas são realizados. Caso este coeficiente seja menor do que zero, evidenciará o reconhecimento oportuno, onde os ganhos são compenentes transitórios nos resultados do período atual e que os mesmos tendem a sofrerem reversões em períodos posteriores. Quando o somatório dos coeficientes $\beta_{2}$ e $\beta_{3}$ forem significativamente menor do que zero, tem-se a ocorrência de comportamento conservador nos resultados. Para verificar se a característica de auditoria independente utilizada afeta no nível de conservadorismo, espera-se que os coeficientes $\beta_{6}$ e $\beta_{7}$ tenham o mesmo comportamento de $\beta_{2}$ e $\beta_{3}$.

\subsubsection{Modelo de mensuração da qualidade de mensuração dos accruals}

A qualidade na mensuração dos accruals foi medido pelo modelo proposto por Dechow e Dichev (2002), conforme equação 3 abaixo:

$$
\Delta \mathrm{WC}_{\mathrm{t}}=\beta_{0}+\beta_{1} \mathrm{CF}_{\mathrm{it}-1}+\beta_{2} \mathrm{CF}_{\mathrm{it}}+\beta_{3} \mathrm{CF}_{\mathrm{it}+1}+\varepsilon_{\mathrm{it}}
$$

em que: 
$\Delta \mathrm{WC}_{\mathrm{it}}=$ variação dos accruals do capital de giro da empresa $i$ do período $t$ - 1 para o período $t$, ponderada pelos ativos totais no final do período $t-1$;

$\mathrm{CF}_{\text {it-1 }}=$ fluxos de caixa no período $t-1$, ponderados pelos ativos totais no final do período $t-2$

$\mathrm{CF}_{\text {it }}=$ fluxos de caixa no período $t$, ponderados pelos ativos totais no final do período $t$ 1 ;

$\mathrm{CF}_{\mathrm{it}+1}=$ fluxos de caixa no período $t+1$, ponderados pelos ativos totais no final do período $t$

$\varepsilon_{\mathrm{it}}=$ erro de estimativa nos accruals no período $t$.

A variação do capital de giro $\left(\Delta \mathrm{WC}_{\mathrm{it}}\right)$ foi utilizada como proxy dos accruals, uma vez que, conforme exposto por Dechow e Dichev (2002), tais variáveis (acrruals e variação do capital de giro), apresentam forte correlação positiva. Sendo a variação do capital de giro $\left(\Delta \mathrm{WC}_{\mathrm{it}}\right)$ coletada diretamente do software da Thompson Reuters, mensurada da seguinte forma (Equação 4):

$$
\Delta \mathrm{WC}_{\mathrm{it}}=\Delta \mathrm{CR}_{\mathrm{it}}+\Delta \text { Estoques }_{\mathrm{it}}-\Delta \mathrm{CP}_{\mathrm{it}}-\Delta \mathrm{IP}_{\mathrm{it}}+\Delta \mathrm{OA}_{\mathrm{it}}
$$

Onde:

$\Delta \mathrm{CR}_{\mathrm{it}}=$ variação do contas a receber da empresa $i$ do período $t-1$ para o período $t$, ponderada pelos ativos totais no final do período $t-1$;

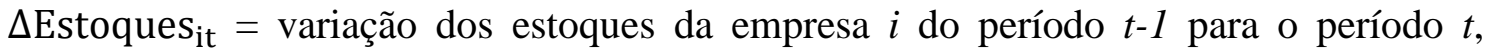
ponderada pelos ativos totais no final do período $t-1$;

$\Delta \mathrm{CP}_{\mathrm{it}}=$ variação das contas a pagar da empresa $i$ do período $t-1$ para o período $t$, ponderada pelos ativos totais no final do período $t-1$;

$\Delta \mathrm{IP}_{\text {it }}=$ variação dos impostos a pagar da empresa $i$ do período $t-1$ para o período $t$, ponderada pelos ativos totais no final do período $t-1$;

$\Delta \mathrm{OA}_{\mathrm{it}}=$ variação de outros ativos da empresa $i$ do período $t-1$ para o período $t$, ponderada pelos ativos totais no final do período $t-1$;

Dechow e Dichev (2002) explicam que os resíduos da regressão (equação 4) são os accruals que não tem vinculo com a realização dos fluxos de caixa, e o desvio-padrão destes resíduos é uma medida de qualidade da mensuração dos accruals. Assim, tem-se que, quanto maior este desvio-padrão, menor será a qualidade na mensuração dos 
accruals. Para verificar se as proxies da qualidade da auditoria influencia na qualidade da mensuração dos accruals realizou-se testes de médias a um nível de significância de 5\%.

\subsubsection{Modelo de mensuração do value relevance}

A última qualidade da informação a ser analisada foi o value relevance e para a realização desta análise foi utilizado o modelo de Ohlson (1995), onde o mesmo baseiase em números contábeis, conforme equação 5 abaixo:

$$
P_{i t}=\beta_{0}+\beta_{1} P L_{i t}+\beta_{2} L_{i t}^{a}+\beta_{3} Q A_{i t}+\varepsilon_{i t}
$$

em que:

$\mathrm{P}_{\mathrm{t}}=$ valor de mercado da companhia i no ano $\mathrm{t}$;

$\mathrm{PL}_{\mathrm{t}}=$ patrimônio líquido da companhia i no período $\mathrm{t}$;

$\mathrm{L}_{\mathrm{it}}^{\mathrm{a}}=$ lucro anormal da companhia i no período t;

$\mathrm{QA}_{\mathrm{it}}=$ proxies para qualidade da auditoria da companhia i no período $\mathrm{t}$;

$\varepsilon_{\text {it }}=$ erro da regressão.

Para o cálculo do lucro anormal ( $\mathrm{L}_{\mathrm{it}}^{\mathrm{a}}$ ), Ohlson (1992) aborda que é necessário aplicar uma taxa de desconto livre de risco sobre o patrimônio liquido inicial do período analisado e subtrair o valor encontrado do lucro do período, conforme equação 6 . A taxa de desconto livre de risco utilizada para o cálculo do lucro anormal foi a taxa acumulada da poupança no período referente a análise ${ }^{4}$, assim como utilizado em outros trabalhos nacionais (COELHO; AGUIAR; LOPES, 2011; GIRÃO, 2012). Com isto, tem-se a seguinte equação:

$$
\mathrm{L}_{\mathrm{it}}^{\mathrm{a}}=\mathrm{L}_{\mathrm{it}}-\mathrm{r} * \mathrm{PL} \mathrm{L}_{\mathrm{it}-1}
$$

Em que:

$\mathrm{L}_{\mathrm{it}}^{\mathrm{a}}=$ lucro anormal da companhia i no período $\mathrm{t}$;

$\mathrm{L}_{\mathrm{it}}=$ lucro líquido da companhia i no período $\mathrm{t}$;

$\mathrm{r}=$ taxa de desconto livre de riscos;

$\mathrm{PL}_{\mathrm{it}-1}=$ patrimônio líquido da companhia i no período $\mathrm{t}-1$.

Para as análises realizadas foram utilizados o modelo de regressão com dados em painel desbalanceado. Então, foram necessários testes estatísticos para verificar se a

\footnotetext{
${ }^{4}$ As taxas de desconto utilizadas foram coletadas no site Portal Brasil (http://www.portalbrasil.net/poupanca_mensal.htm)
} 
estimação dos modelos ocorreria por Pooled Ordinary Least Squares (POLS), efeitos aleatórios ou efeitos fixos para todos os grupos analisados. Inicialmente, mediante o teste de Chow, verificou a adequação do modelo para estimadores por efeitos fixos e POLS, onde o teste rejeitou a hipótese nula para estimação por modelo POLS. Subsequentemente, utilizou-se o teste de Breusch-Pagan, para analisar a estimação por POLS ou efeitos aleatórios, rejeitando a hipótese nula de adequação do modelo por estimadores por POLS. Por último, realizou-se o teste de Hausman para verificar se a estimação seria feita mediante efeitos fixos ou aleatórios, onde a hipótese nula de consistência dos estimadores por efeitos aleatórios foi rejeitada. Então, os modelos utilizados foram estimados com dados em painel com efeitos fixos.

Visando atribuir melhor robustez dos parâmetros estimados pelos modelos de regressão das análises dos dados em painel, verificou-se os pressupostos básicos de heterocedasticidade e de normalidade. Por meio do teste de Wald, observou-se a presença de heterocedasticidade, sendo os modelos estimados com erros-padrão robustos. Tratando dos pressupostos da normalidade, os resíduos das regressões apresentaram distribuição não normal ao nível de significância de 5\%. Porém, com base no Teorema do Limite Central e na Lei dos Grandes Números, esse pressuposto pode ser relaxado (BROOKS, 2008), visto o grande número de observação de cada um dos modelos utilizados pelo presente estudo.

\subsubsection{Definição das variáveis da qualidade da auditoria}

Neste tópico foram apresentadas as variáveis das características da auditoria independente (proxies para qualidade da auditoria) utilizadas pelo presente estudo.

a) Tamanho da Firma de Auditoria $\left(\mathrm{TAM}_{\mathrm{it}}\right)$

A primeira proxy da qualidade da auditoria utilizada foi o tamanho da firma de auditoria. Conforme tratado na teoria, utilizam-se as maiores firmas, conhecidas com as Big 4 como proxy para tamanho da firma de auditoria. Com isto, o presente estudo utilizou uma dummy 1 para as firmas de auditoria Big 4 e a dummy 0 para as demais firmas.

b) Tempo de Relacionamento entre a Firma de Auditoria e o Cliente (TENURE it $_{\text {) }}$

Para a segunda proxy de qualidade de auditoria analisada foi verificado a quantidade de anos consecutivos de relacionamento entre a firma de auditoria e o cliente.

c) Serviços não Relacionados a Auditoria $\left(\mathrm{NAS}_{\mathrm{it}}\right)$ 
A firma de auditoria que presta serviços não relacionados a auditoria no ano analisado foram classificadas com variável dummy 1, enquanto que as demais, aquelas que prestaram apenas serviços relacionados a auditoria foram classificadas como variável dummy 0.

\section{d) Presença do Comitê de Auditoria $\left(\mathrm{AUDCOM}_{\mathrm{it}}\right)$}

A quarta característica de qualidade de auditoria analisada foi a presença de comitê de auditoria na estrutura organizacional da companhia auditada. Para as companhias que apresentam tal comitê utilizou-se a dummy 1 e para as que não apresentaram comitê classificou-se como a variável dummy 0.

\section{e) Tempo de Emissão do Relatório de Auditoria (DELAY it)}

Para a última característica de auditoria analisada, foi utilizado como variável o somatório da quantidade de dias para a emissão do relatório de auditoria desde o último dia do exercício social auditado.

Quadro 1 - Quadro Metodológico da Pesquisa

\begin{tabular}{|c|c|c|c|}
\hline $\begin{array}{c}\text { Título da } \\
\text { Dissertação }\end{array}$ & \multicolumn{3}{|c|}{$\begin{array}{l}\text { A influência de características da auditoria independente na qualidade da informação } \\
\text { contábil }\end{array}$} \\
\hline $\begin{array}{l}\text { Questão de } \\
\text { Pesquisa }\end{array}$ & \multicolumn{3}{|c|}{$\begin{array}{l}\text { Qual a influência de características da qualidade da auditoria independente na } \\
\text { qualidade da informação contábil? }\end{array}$} \\
\hline $\begin{array}{l}\text { Objetivo } \\
\text { Geral }\end{array}$ & \multicolumn{3}{|c|}{$\begin{array}{l}\text { Verificar a influência de características da auditoria independente na qualidade das } \\
\text { informações contábeis nas companhias abertas brasileiras. }\end{array}$} \\
\hline \multirow{6}{*}{$\begin{array}{l}\text { Objetivos } \\
\text { Específicos }\end{array}$} & $\mathrm{OE}_{1}$ & \multicolumn{2}{|c|}{$\begin{array}{l}\text { Evidenciar o papel dos auditores independentes na validação da informação } \\
\text { contábil entregue via relatórios financeiros }\end{array}$} \\
\hline & $\mathrm{OE}_{2}$ & \multicolumn{2}{|c|}{$\begin{array}{l}\text { Verificar a influência do tamanho da firma de auditoria na qualidade da } \\
\text { informação contábil }\end{array}$} \\
\hline & $\mathrm{OE}_{3}$ & \multicolumn{2}{|c|}{$\begin{array}{l}\text { Avaliar de que forma o período de relacionamento entre a firma de auditoria e } \\
\text { cliente afeta na qualidade da informação contábil }\end{array}$} \\
\hline & $\mathrm{OE}_{4}$ & \multicolumn{2}{|c|}{$\begin{array}{l}\text { Averiguar como os serviços de não auditoria, prestados por firmas de auditoria, } \\
\text { afetam na qualidade da informação contábil }\end{array}$} \\
\hline & $\mathrm{OE}_{5}$ & \multicolumn{2}{|c|}{$\begin{array}{l}\text { Analisar a relação entre a existência do comitê de auditoria e a qualidade da } \\
\text { informação contábil }\end{array}$} \\
\hline & $\mathrm{OE}_{6}$ & \multicolumn{2}{|c|}{$\begin{array}{l}\text { Investigar a influência do tempo de emissão do relatório de auditoria na } \\
\text { qualidade da informação contábil }\end{array}$} \\
\hline \multirow{3}{*}{$\begin{array}{c}\text { Suporte } \\
\text { Técnico da } \\
\text { Pesquisa }\end{array}$} & \multirow{3}{*}{\multicolumn{2}{|c|}{$\begin{array}{l}\text { Quadro de Referência } \\
\text { Téorica }\end{array}$}} & 1) Auditoria Independente \\
\hline & & & 2) Qualidad \\
\hline & & & 3) Qual \\
\hline \multirow{5}{*}{$\begin{array}{c}\text { Suporte } \\
\text { Metodológico } \\
\text { da Pesquisa }\end{array}$} & Parac & gma Metodológico & Positivista \\
\hline & Natu & a da Pesquisa & Aplic \\
\hline & Obje & o da Pesquisa & Descritiva \\
\hline & \multicolumn{2}{|c|}{ Processo de Amostragem } & $\begin{array}{l}\text { Não probabilística } \\
\text { População: Todas as companhias abertas brasileiras } \\
\text { Amostra: As companhias abertas brasileiras com os } \\
\text { dados necessários para estimação dos modelos utilizados. }\end{array}$ \\
\hline & \multicolumn{2}{|c|}{$\begin{array}{l}\text { Método de Tratamento } \\
\text { dos dados }\end{array}$} & $\begin{array}{l}\text { Estatísticas Descritivas e regressões múltiplas estimadas } \\
\text { mediante dados em painel desbalanceado. }\end{array}$ \\
\hline
\end{tabular}

Fonte: Própria 


\section{ANÁLISE E INTERPRETAÇÃO DOS RESULTADOS}

\subsection{ESTATÍSTICAS DESCRITIVAS}

As tabelas 1, 2 e 3 apresentam as estatísticas descritivas do modelo de mensuração dos três atributos da qualidade da informação contábil analisados por esta pesquisa. Na tabela 1, a qual mostra as variáveis do modelo de conservadorismo, pode-se verificar que, em média, a variável dos lucros, tanto de t-1 para t, quanto de t-2 para t-1, foi negativo, podendo inferir sobre uma queda no resultado das companhias.

Tabela 1 - Estatísticas Descritivas - Modelo Conservadorismo

\begin{tabular}{lcc}
\hline & $\Delta \mathrm{NI}_{\mathrm{it}}$ & $\Delta \mathrm{NI}_{\mathrm{it}-1}$ \\
\hline Média & $-0,1138$ & $-0,0705$ \\
Mediana & $-0,1153$ & $-0,0846$ \\
Desvio-Padrão & 1,2502 & 1,319 \\
$\mathrm{~N}$ & 1.310 & 1.310 \\
\hline Fonte: Própria &
\end{tabular}

A tabela 2 contem as variáveis utilizadas no modelo de qualidade na mensuração dos accruals. Nesta tabela pode-se verificar que em média a variação do capital de giro $\left(\Delta \mathrm{WC}_{\mathrm{it}}\right)$ foi negativa, enquanto que dos fluxos de caixa utilizado foi positiva.

Tabela 2 - Estatísticas Descritivas - Modelo Qualidade na Mensuração dos Accruals

\begin{tabular}{lcccc}
\hline & $\Delta \mathrm{WC}_{\mathrm{it}}$ & $\mathrm{CF}_{\text {it-1 }}$ & $\mathrm{CF}_{\mathrm{it}}$ & $\mathrm{CF}_{\mathrm{it}+1}$ \\
\hline Média & $-0,4061$ & 0,0115 & 0,0049 & 0,0036 \\
Mediana & $-0,4729$ & 0,0044 & 0,0023 & 0,0023 \\
Desvio-Padrão & 1,0914 & 0,0836 & 0,0784 & 0,0693 \\
$\mathrm{~N}$ & 982 & 982 & 982 & 982 \\
\hline \multicolumn{2}{c}{ Fonte: Própria } & & &
\end{tabular}

Enquanto que, para o modelo de Value Relevance, contidos na tabela 3, pode-se verificar que, para a amostra analisada, o valor de mercado apresentou maior desviopadrão que as demais variáveis e que o lucro anormal mostrou-se, em média, positivo.

Tabela 3 - Estatísticas Descritivas - Modelo Value Relevance

\begin{tabular}{lccc}
\hline & $\mathrm{P}_{\mathrm{it}}$ & $\mathrm{PL}_{\mathrm{it}}$ & $\mathrm{L}_{\mathrm{it}}^{\mathrm{a}}$ \\
\hline Média & 0,7372 & 0,4522 & 0,0016 \\
Mediana & 0,5139 & 0,4281 & 0,0043 \\
Desvio-Padrão & 0,6744 & 0,2336 & 0,0722 \\
$\mathrm{~N}$ & 1.169 & 1.169 & 1.169 \\
\hline Fonte: Própria & &
\end{tabular}

Fonte: Própria

A tabela 4 apresenta as estatísticas referente a quantidade de companhias auditadas pelas Big 4 e demais firmas de auditoria (Não Big 4) segregada por atributo da qualidade da informação contábil. Pode-se verificar que, para os três atributos analisados, mais de $70 \%$ das companhias referente a amostra foram auditadas por Big 4, demonstrando que tais firmas conseguem capturar a maior parcela de cliente. Com isto, tais firmas são 
consideradas, teoricamente, aquelas que apresentam uma melhor qualidade dos serviços prestados, pela captação da maior parcela do mercado, fazendo com que maiores receitas sejam auferidas e, consequentemente, haja maior investimento nas suas atividades.

Tabela 4 - Quantidade de companhias auditadas por Big 4 x Outras Firmas (Não Big 4)

\begin{tabular}{lccccc}
\hline & \multicolumn{2}{c}{ Big 4 } & \multicolumn{2}{c}{ Não Big 4 } & \multirow{2}{*}{ TOTAL } \\
\cline { 1 - 4 } & Total & $\%$ & Total & $\%$ & \\
\hline Conservadorismo & 920 & 70,23 & 390 & 29,77 & 1.310 \\
Qualidade na Mensuração & 713 & 72,63 & 269 & 27,39 & 982 \\
dos Accruals & 880 & 75,28 & 289 & 24,72 & 1.169 \\
Value Relevance & & &
\end{tabular}

Fonte: Própria

Conforme exposto na tabela 5 , pode-se verificar que a maioria das companhias contidas nas amostras analisadas presentaram apenas serviços relacionados a auditoria, girando em torno de $80 \%$ para os três atributos analisados. Esse quantitativo pode ser justificado por restrições acerca da prestação de outros serviços por firmas de auditoria, com o intuito de não prejudicar a independência do auditor independente.

Tabela 5 - Quantidade de firmas de auditoria que prestaram serviços não relacionados a auditoria

\begin{tabular}{lccccc}
\hline & \multicolumn{2}{c}{ Outros Serviços } & \multicolumn{2}{c}{ Apenas Auditoria } & \multirow{2}{*}{ TOTAL } \\
\cline { 1 - 4 } & Total & $\%$ & Total & $\%$ & \\
\cline { 1 - 4 } Conservadorismo & 239 & 18,24 & 1.071 & 81,76 & \multirow{2}{*}{1.310} \\
Qualidade na Mensuração & 187 & 19,04 & 795 & 80,96 & 982 \\
dos Accruals & 242 & 20,70 & 927 & 79,30 & 1.169 \\
\cline { 1 - 3 } Value Relevance & & &
\end{tabular}

Fonte: Própria

A tabela 6 apresenta a quantidade de companhias que apresentam comitê de auditoria em sua estrutura organizacional. Pode-se verificar que a maioria das companhias não apresentaram tal comitê, o qual pode ser uma característica que pode afetar a independência dos serviços de auditoria, uma vez que, neste caso, a contratação, bem como a fiscalização desses serviços caberá a administração da companhia.

Tabela 6 - Quantidade de companhias com presença ou não do Comitê de Auditoria

\begin{tabular}{lccccc}
\hline & \multicolumn{2}{c}{ Comitê } & \multicolumn{2}{c}{ Sem Comitê } & \multirow{2}{*}{ TOTAL } \\
\cline { 1 - 4 } & Total & $\%$ & Total & $\%$ & \\
\hline Conservadorismo & 325 & 24,81 & 985 & 75,19 & 1.310 \\
Qualidade na Mensuração & 255 & 25,97 & 727 & 74,03 & 982 \\
dos Accruals & 301 & 25,75 & 868 & 74,25 & 1.169 \\
Value Relevance & & &
\end{tabular}

Fonte: Própria

\subsection{ANÁLISE DOS RESULTADOS DA PESQUISA}

4.2.1 Análise da influência das características da auditoria independente sobre o conservadorismo incondicional

Neste tópico, foram analisados, inicialmente, a influência de características da auditoria independente sobre o conservadorismo condicional, conforme o modelo de Ball e Shivakumar (2005). 
4.2.1.1 Análise da influência do tamanho da firma de auditoria independente sobre o conservadorismo incondicional

Foram realizadas regressões referentes aos dois modelos, conforme abordado na metodologia. Primeiramente do modelo original, o qual se repete ao longo das análises das demais características de auditoria independente. Nesta análise, pode-se verificar que a variável $\Delta \mathrm{NI}_{\mathrm{it}-1}\left(\beta_{2}\right)$ é estatisticamente diferente de zero, logo pode-se inferir que os resultados positivos divulgados pelas companhias sofrem reversões em períodos posteriores, podendo indicar a existência de reconhecimento oportuno de boas noticias, podendo sinalizar uma certa agressividade por parte das companhias, visto que as mesmas estão aumentando seus ganhos ao longo do período analisado. Uma vez que a variável $\Delta \mathrm{NI}_{\mathrm{it}-1}{ }^{*} \mathrm{D} \Delta \mathrm{NI}_{\mathrm{it}-1}$ não é significante e nem negativa, não pode-se afirmar que as companhias apresentam indícios de reconhecimento mais rápido das perdas econômicas frente os ganhos.

$\mathrm{Na}$ análise do modelo adaptado, levando em consideração do tamanho da firma de auditoria (TAMit), pode-se verificar que os coeficientes $\beta_{2}, \beta_{3}, \beta_{6}$ e $\beta_{7}$ não são significativamente igual a zero, com isto, pode-se verificar que as companhias não apresentam maior nível de comportamento conservador quando auditadas por maiores firmas de auditoria.

Tabela 7 - Análise da influência do Tamanho da Firma de Auditoria sobre o Conservadorismo Condicional

\begin{tabular}{|c|c|c|c|c|}
\hline & \multicolumn{2}{|c|}{ Modelo Original } & \multicolumn{2}{|c|}{ Modelo Adaptado } \\
\hline & Coef. & $p$-value & Coef. & p-value \\
\hline Constante & $-0,154$ & 0,020 & $-0,306$ & 0,021 \\
\hline $\mathrm{D} \Delta \mathrm{NI}_{\mathrm{it}-1}$ & 0,128 & 0,137 & 0,395 & 0,015 \\
\hline$\Delta \mathrm{NI}_{\mathrm{it}-1}$ & $-0,201$ & 0,002 & $-0,084$ & 0,429 \\
\hline$\Delta \mathrm{NI}_{\mathrm{it}-1}{ }^{*} \mathrm{D} \Delta \mathrm{NI}_{\mathrm{it}-1}$ & 0,105 & 0,327 & $-0,015$ & 0,927 \\
\hline $\mathrm{TAM}_{\mathrm{it}}$ & & & 0,222 & 0,174 \\
\hline $\mathrm{TAM}_{\mathrm{it}}{ }^{*} \mathrm{D} \Delta \mathrm{NI}_{\mathrm{it}-1}$ & & & $-0,381$ & 0,036 \\
\hline $\mathrm{TAM}_{\mathrm{it}} * \Delta \mathrm{NI}_{\mathrm{it}-1}$ & & & $-0,183$ & 0,132 \\
\hline $\mathrm{TAM}_{\mathrm{it}}{ }^{*} \mathrm{D} \Delta \mathrm{NI}_{\mathrm{it}-1}{ }^{*} \Delta \mathrm{NI}_{\mathrm{it}-1}$ & & & 0,198 & 0,294 \\
\hline $\mathrm{R}^{2}$ & 0,280 & & 0.284 & \\
\hline $\mathrm{R}^{2}$ Ajustado & 0,042 & & 0,047 & \\
\hline Estatística F & 11,871 & 0,000 & 6,180 & 0,000 \\
\hline Teste de Wald & 6,367 & 0,000 & 2,123 & 0,000 \\
\hline Teste de Normalidade & 278,33 & 0,000 & 274,165 & 0,000 \\
\hline Durbin Watson & 1,778 & & 1,778 & \\
\hline $\mathrm{N}$ & 1310 & & 1310 & \\
\hline
\end{tabular}

Fonte: Própria

4.2.1.2 Análise da influência do período de relacionamento entre a firma de auditoria independente e a companhia auditada sobre o conservadorismo incondicional

A segunda característica da auditoria a ser analisada em relação a influência no nível de conservadorismo condicional foi o período de relacionamento entre a firma de auditoria e a companhia auditada (TENURE $\mathrm{T}_{\mathrm{it}}$ ). Esta análise baseia-se na quantidade de exercícios sociais em que a firma de auditoria mantém relacionamento com o seu cliente. Espera-se que, visto possível diminuição da independência do auditor, causado pelo maior tempo de relacionamento entre a parte, haja uma perda na qualidade, tanto da 
auditoria, como da informação contábil, afetando o nível de conservadorismo das companhias.

Verifica-se que, no modelo adaptado com a variável da qualidade da auditoria (TENURE $\left._{i t}\right)$, a variável $\Delta$ NIit-1 $\left(\beta_{2}\right)$ apresenta significância estatística a um nível de $1 \%$, onde tal resultado mostra a ocorrência de reconhecimento oportuno dos ganhos, podendose inferir que os resultados positivos divulgados pelas empresas sofrem reversões em períodos subsequentes.

Porém, variável TENURE Tt $^{*} \mathrm{D} \Delta \mathrm{NIit}-1 * \Delta \mathrm{NIit}^{1}\left(\beta_{7}\right)$, apresentou significância e sinal negativo, o que indica que as companhias auditadas por firmas de auditoria por um período maior de tempo apresentam um nível de comportamento mais conservador, reconhecendo oportunamente as perdas econômicas. A análise do somatório dos coeficientes $\beta_{2}, \beta_{3}, \beta_{6}$ e $\beta_{7}(-0,080)$, quando comparado com o somatório $\beta_{2}$ e $\beta_{3}(-0,068)$ permitir confirmar os resultados da análise do coeficiente $\beta_{7}$. Com base nesses resultados, o tempo de relacionamento entre a firma de auditoria e o cliente, apesar de defendido teoricamente como perda da independência e consequemente, impacto negativo na qualidade da informação contábil, quanto maior for este tempo, pode-se sugerir que o maior tempo de relacionamento pode melhorar a informação contábil reportadas, uma vez que o próprio auditor terá maior grau de conhecimento acerca das atividades desenvolvidas pela empresa auditada.

Tabela 8 - Análise da influência do Período de Relacionamento entre a Firma de Auditoria e o cliente sobre o Conservadorismo Condicional

\begin{tabular}{|c|c|c|c|c|}
\hline & \multicolumn{2}{|c|}{ Modelo Original } & \multicolumn{2}{|c|}{ Modelo Adaptado } \\
\hline & Coef. & $p$-value & Coef. & $p$-value \\
\hline Constante & $-0,154$ & 0,020 & 0,042 & 0,724 \\
\hline $\mathrm{D} \Delta \mathrm{NI}_{\mathrm{it}-1}$ & 0,128 & 0,137 & 0,025 & 0,881 \\
\hline$\Delta \mathrm{NI}_{\mathrm{it}-1}$ & $-0,201$ & 0,002 & $-0,405$ & 0,001 \\
\hline$\Delta \mathrm{NI}_{\mathrm{it}-1}{ }^{*} \mathrm{D} \Delta \mathrm{NI}_{\mathrm{it}-1}$ & 0,105 & 0,327 & 0,337 & 0,081 \\
\hline TENURE $_{\text {it }}$ & & & $-0,092$ & 0,020 \\
\hline TENURE $_{\text {it }} *$ D $\Delta \mathrm{NI}_{\mathrm{it}-1}$ & & & 0,046 & 0,453 \\
\hline TENURE $_{\mathrm{it}} * \Delta \mathrm{NI}_{\mathrm{it}-1}$ & & & 0,094 & 0,014 \\
\hline TENURE $_{\mathrm{it}}{ }^{*} \mathrm{D} \Delta \mathrm{NI}_{\mathrm{it}-1}{ }^{*} \Delta \mathrm{NI}_{\mathrm{it}-1}$ & & & $-0,106$ & 0,077 \\
\hline $\mathrm{R}^{2}$ & 0,280 & & 0,284 & \\
\hline $\mathrm{R}^{2}$ Ajustado & 0,042 & & 0,047 & \\
\hline Estatística F & 11,871 & 0,000 & 6,136 & 0,000 \\
\hline Teste de Wald & 6,367 & 0,000 & 1,301 & 0,000 \\
\hline Teste de Normalidade & 278,33 & 0,000 & 285,78 & 0,000 \\
\hline Durbin Watson & 1,778 & & 1,783 & \\
\hline $\mathrm{N}$ & 1310 & & 1310 & \\
\hline
\end{tabular}

Fonte: Própria

4.2.1.3 Análise da influência da realização de serviços de não auditoria pela firma de auditoria independente sobre o conservadorismo incondicional

A realização de serviços não relacionados a auditoria foi a terceira característica da auditoria analisada. Visto a dependência econômica e o próprio retorno financeiro que a firma de auditoria tem com a prestação destes serviços, espera-se que haja uma influência negativa na qualidade da informação contábil. 
Tabela 9 - Análise da influência de Serviços não Relacionados a Auditoria sobre o Conservadorismo Condicional

\begin{tabular}{|c|c|c|c|c|}
\hline & \multicolumn{2}{|c|}{ Modelo Original } & \multicolumn{2}{|c|}{ Modelo Adaptado } \\
\hline & Coef. & p-value & Coef. & p-value \\
\hline Constante & $-0,154$ & 0,020 & $-0,158$ & 0,032 \\
\hline $\mathrm{D} \Delta \mathrm{NI}_{\mathrm{it}-1}$ & 0,128 & 0,137 & 0,086 & 0,353 \\
\hline$\Delta \mathrm{NI}_{\text {it-1 }}$ & $-0,201$ & 0,002 & $-0,165$ & 0,028 \\
\hline$\Delta \mathrm{NI}_{\mathrm{it}-1}{ }^{*} \mathrm{D} \Delta \mathrm{NI}_{\mathrm{it}-1}$ & 0,105 & 0,327 & 0,002 & 0,984 \\
\hline $\mathrm{NAS}_{\text {it }}$ & & & 0,003 & 0,980 \\
\hline $\mathrm{NAS}_{\mathrm{it}} * \mathrm{D} \Delta \mathrm{NI}_{\mathrm{it}-1}$ & & & 0,215 & 0,293 \\
\hline $\mathrm{NAS}_{\mathrm{it}} * \Delta \mathrm{NI}_{\mathrm{it}-1}$ & & & $-0,189$ & 0,086 \\
\hline $\mathrm{NAS}_{\text {it }}{ }^{*} \mathrm{D} \Delta \mathrm{NI}_{\mathrm{it}-1}{ }^{*} \Delta \mathrm{NI}_{\mathrm{it}-1}$ & & & 0,490 & 0,016 \\
\hline $\mathrm{R}^{2}$ & 0,280 & & 0,286 & \\
\hline $\mathrm{R}^{2}$ Ajustado & 0,042 & & 0,050 & \\
\hline Estatística F & 11,871 & 0,000 & 8,408 & 0,000 \\
\hline Teste de Wald & 6,367 & 0,000 & 1,974 & 0,000 \\
\hline Teste de Normalidade & 278,33 & 0,000 & 277,03 & 0,000 \\
\hline Durbin Watson & 1,778 & & 1,795 & \\
\hline $\mathrm{N}$ & 1310 & & 1310 & \\
\hline
\end{tabular}

Fonte: Própria

Conforme visto na tabela acima, pode-se verificar que, apesar do coeficiente $\beta_{7}$ ser estatisticamente diferente de zero $\left(\beta_{7}>0\right)$, demonstrando que as companhias auditadas por firmas de auditoria que prestam outros serviços são menos propensas a reconhecer com oportunismo as suas perdas econômicas. Tal ponto, pode ser confirmado pelo somatório dos coeficientes $\beta_{2}, \beta_{3}, \beta_{6}$ e $\beta_{7}$ que totaliza 0,138 , quando comparada com o somatório dos coeficientes $\beta_{2}$ e $\beta_{3}(-0,163)$, afetando negativamente na qualidade da informação contábil, mediante a redução do nível de conservadorismo dos números contábeis.

4.2.1.4 Análise da influência da existência de comitê de auditoria na companhia auditada sobre o conservadorismo incondicional

O comitê de auditoria constitui-se como um "setor" da companhia, com independência frente a administração da mesma. Dentre suas atribuições, comumente, estar a de fiscalizar as atividades desenvolvidas pelos auditores independentes, bem como verificar os próprios controles internos da sua empresa. Com isto, espera-se que a presença do comitê de auditoria afete positivamente na qualidade da informação contábil, mediante a inibição de comportamentos oportunisticas por parte da gestão da companhia. Na tabela 10 abaixo, é apresentado o resultado do modelo de conservadorismo contendo a variável dummy de presença do comitê de auditoria na empresa. 
Tabela 10 - Análise da Presença do Comitê de Auditoria sobre o Conservadorismo Condicional

\begin{tabular}{|c|c|c|c|c|}
\hline & \multicolumn{2}{|c|}{ Modelo Original } & \multicolumn{2}{|c|}{ Modelo Adaptado } \\
\hline & Coef. & $p$-value & Coef. & p-value \\
\hline Constante & $-0,154$ & 0,020 & $-0,153$ & 0,067 \\
\hline $\mathrm{D} \Delta \mathrm{NI}_{\mathrm{it}-1}$ & 0,128 & 0,137 & 0,203 & 0,045 \\
\hline$\Delta \mathrm{NI}_{\mathrm{it}-1}$ & $-0,201$ & 0,002 & $-0,168$ & 0,025 \\
\hline$\Delta \mathrm{NI}_{\mathrm{it}-1}{ }^{*} \mathrm{D} \Delta \mathrm{NI}_{\mathrm{it}-1}$ & 0,105 & 0,327 & 0,049 & 0,669 \\
\hline AUDCOM $_{\text {it }}$ & & & $-0,002$ & 0,988 \\
\hline $\operatorname{AUDCOM}_{\mathrm{it}} * \mathrm{D} \Delta \mathrm{NI}_{\mathrm{it}-1}$ & & & $-0,299$ & 0,105 \\
\hline $\operatorname{AUDCOM}_{\mathrm{it}} * \Delta \mathrm{NI}_{\mathrm{it}-1}$ & & & $-0,164$ & 0,223 \\
\hline $\operatorname{AUDCOM}_{\mathrm{it}}{ }^{*} \mathrm{D} \Delta \mathrm{NI}_{\mathrm{it}-1}{ }^{*} \Delta \mathrm{NI}_{\mathrm{it}-1}$ & & & 0,273 & 0,312 \\
\hline $\mathrm{R}^{2}$ & 0,280 & & 0,284 & \\
\hline $\mathrm{R}^{2}$ Ajustado & 0,042 & & 0,048 & \\
\hline Estatística F & 11,871 & 0,000 & 6,052 & 0,000 \\
\hline Teste de Wald & 6,367 & 0,000 & 6,425 & 0,000 \\
\hline Teste de Normalidade & 278,33 & 0,000 & 272,332 & 0,000 \\
\hline Durbin Watson & 1,778 & & 1,804 & \\
\hline $\mathrm{N}$ & 1310 & & 1310 & \\
\hline
\end{tabular}

Fonte: Própria

Com base na tabela 10 , pode-se verificar que o coeficiente $\left(\beta_{2}\right)$ é estatisticamente menor do que zero, o que implica no reconhecimento oportuno, onde os ganhos são componentes transitórios nos resultados do atual período e que estes tendem a sofrer reversões em períodos posteriores. Como os coeficientes $\beta_{3}, \beta_{6}$ e $\beta_{7}$ não são significantes, não pode-se inferir sobre um maior nível de conservadorismo por parte das companhias que apresentam comitê de auditoria em sua estrutura organizacional.

4.2.1.5 Análise da influência do tempo de emissão do relatório de auditoria independente sobre o conservadorismo incondicional

A última característica da auditoria analisada foi o tempo de emissão do relatório de auditoria. O cálculo do tempo de emissão do relatório se deu pela quantidade de dias do término do exercício social até referida data do relatório. Assim como na análise da presença do comitê de auditoria, pode-se verificar que o coeficiente $\left(\beta_{2}\right)$ é estatisticamente menor, sendo realizado a mesma observação da análise anterior. Porém, visto que o $\beta_{3}$ é estatisticamente menor do que zero, ressalta-se a ocorrência de reconhecimento oportuno das perdas. 
Tabela 11 - Análise do Tempo de Emissão do Relatório de Auditoria sobre o Conservadorismo Condicional

\begin{tabular}{|c|c|c|c|c|}
\hline & \multicolumn{2}{|c|}{ Modelo Original } & \multicolumn{2}{|c|}{ Modelo Adaptado } \\
\hline & Coef. & p-value & Coef. & p-value \\
\hline Constante & $-0,154$ & 0,020 & 0,086 & 0,527 \\
\hline $\mathrm{D} \Delta \mathrm{NI}_{\mathrm{it}-1}$ & 0,128 & 0,137 & $-0,348$ & 0,049 \\
\hline$\Delta \mathrm{NI}_{\mathrm{it}-1}$ & $-0,201$ & 0,002 & $-0,487$ & 0,000 \\
\hline$\Delta \mathrm{NI}_{\mathrm{it}-1}{ }^{*} \mathrm{D} \Delta \mathrm{NI}_{\mathrm{it}-1}$ & 0,105 & 0,327 & 0,181 & 0,461 \\
\hline DELAY $_{\text {it }}$ & & & $-0,003$ & 0,048 \\
\hline DELAY $_{\text {it }} * \mathrm{D} \Delta \mathrm{NI}_{\mathrm{it}-1}$ & & & 0,006 & 0,004 \\
\hline DELAY $_{\mathrm{it}} * \Delta \mathrm{NI}_{\mathrm{it}-1}$ & & & 0,004 & 0,022 \\
\hline $\operatorname{DELAY}_{\mathrm{it}}{ }^{*} \mathrm{D} \Delta \mathrm{NI}_{\mathrm{it}-1}{ }^{*} \Delta \mathrm{NI}_{\mathrm{it}-1}$ & & & $-0,001$ & 0,700 \\
\hline $\mathrm{R}^{2}$ & 0,280 & & 0,286 & \\
\hline $\mathrm{R}^{2}$ Ajustado & 0,042 & & 0,050 & \\
\hline Estatística F & 11,871 & 0,000 & 7,955 & 0,000 \\
\hline Teste de Wald & 6,367 & 0,000 & 3,690 & 0,000 \\
\hline Teste de Normalidade & 278,33 & 0,000 & 274,82 & 0,000 \\
\hline Durbin Watson & 1,778 & & 1,783 & \\
\hline $\mathrm{N}$ & 1310 & & 1310 & \\
\hline
\end{tabular}

Fonte: Própria

Em relação a variável do tempo de emissão do relatório $\left(D_{E L A Y}\right.$ it $)$ não pode inferir nada relacionado a influência da mesma, uma vez que o coeficiente $\beta_{7}$ não apresentou significância estatística.

4.2.2 Análise da influência das características da auditoria independente sobre a qualidade na mensuração dos accruals

O segundo atributo da qualidade da informação contábil analisado foi a qualidade da mensuração dos accruals, utilizando o modelo de Dechow e Dichev (2005). Com isto, a seguir tem-se os resultados da influência das características da auditoria independente, utilizadas como proxies para qualidade da auditoria, sobre este atributo da informação contábil.

4.2.2.1 Análise da influência do tamanho da firma de auditoria independente sobre a qualidade na mensuração dos accruals

A primeira análise referente a possível influência da qualidade da auditoria na qualidade na mensuração dos accruals utilizou-se como proxy para qualidade da auditoria o tamanho da firma de auditoria, neste caso segregado em dois grupos, as companhias auditadas por Big 4 e as auditadas por demais empresas de auditoria. Mediante a utilização do modelo proposto por Dechow e Dichev (2002), estimou-se as médias e os desviospadrão dos accruals contábeis, conforme tabela 12 abaixo: 
Tabela 12 - Análise da influência do Tamanho da Firma de Auditoria sobre a Qualidade da Mensuração dos Accruals

\begin{tabular}{l|r|r}
\hline & Big-4 & Não Big-4 \\
\hline Média & $-0,001$ & $-0,001$ \\
Desvio-Padrão & 0,902 & 0,908 \\
Observações & 713 & 269 \\
\hline Kolmogorov-Smirnov & Statistic & p-value \\
Levene & 1,333 & 0,057 \\
Teste t & 0,499 & 0,480 \\
ANOVA & $-0,002$ & 0,998 \\
Welch & 0,000 & 0,998 \\
Brown-Forsythe & 0,000 & 0,998 \\
\hline Fonte: Proppran & 0,000 & 0,998 \\
\hline
\end{tabular}

Fonte: Própria

Com base nos resultados contidos na tabela, os desvios-padrão dos accruals para os dois grupos seguem uma distribuição normal (teste Komolgorov-Smirnov) e apresentam igualdade das variâncias das amostras (teste Levene), a um nível de significância de 5\%. Com isto, verifica-se na tabela que foram realizados teste de média e que todos os testes apresentaram p-value igual a 0,998, rejeitando a hipótese de existência de diferença entre as médias. Ou seja, pode-se inferir que as companhias auditadas por maiores firmas de auditores tendem a não melhor a qualidade da mensuração dos accruals e, consequentemente, a qualidade da informação contábil.

4.2.2.2 Análise da influência do período de relacionamento entre a firma de auditoria independente e a companhia auditada sobre a qualidade na mensuração dos accruals

O período de relacionamento entre a firma de auditoria e o cliente pode impacta negativamente na independência da relação de negócio entre estas partes. Porém, estudos apontam que quanto maior o tempo de relacionamento entre a firma de auditoria e o cliente, menor o montante dos accruals discricionários da companhia (MYERS; MYERS; OMER, 2003; CHEN; LIN; LIN, 2008).

Com base na tabela 13, o presente estudo pode corroborar com os estudos citados anteriormente, reforçando a tese de que quanto mais tempo uma mesma firma de auditoria permanecem auditando determinada empresa melhor é a qualidade de mensuração dos accruals da mesma, conforme observado no teste de média de Mann-Whitney U ( $p$-value $<5 \%)$.

Apesar de ser amplamente discutido, é importante frisar que a relação entre auditor e cliente não é regido apenas por nível de independência, mas também de competência, onde determinados comportamentos (como por exemplo a manutenção do auditor pelo maior numero de períodos permitidos pela legislação) pode contribuir com a melhor na qualidade da auditoria e, consequentemente, com a qualidade dos relatórios contábeis. 
Tabela 13 - Análise da influência do Período de Relacionamento entre a Firma de Auditoria e o cliente sobre a Qualidade da Mensuração dos Accruals

\begin{tabular}{l|r|r}
\hline & Até 2 anos & Após 2 anos \\
\hline Média & 0,804 & 0,000 \\
Desvio-Padrão & 1,350 & 0,665 \\
Observações & & 713 \\
\hline & Statistic & 269 \\
\hline Kolmogorov-Smirnov & 8,957 & p-value \\
Mann-Whitney U & $-14,337$ & 0,000 \\
\hline
\end{tabular}

Fonte: Própria

4.2.2.3 Análise da influência da realização de serviços de não auditoria pela firma de auditoria independente sobre a qualidade na mensuração dos accruals

Visto a possibilidade de diminuição do nível de independência entre firma de auditoria e cliente, conforme tratado na literatura, por causa da prestação de outros serviços para este, para a qualidade na mensuração dos accruals espera-se que haja um diferença entre as médias das companhias que utilizam de outros serviços dos seus auditores, prejudicando a qualidade da informação contábil.

Após realização do teste de Kolmogorov-Smirnov, onde verificou-se que a amostra consiste em uma distribuição não normal, foi realizado o teste de médias não paramétrico de Mann-Whitney U, mas, uma vez que seu $p$-value foi superar a 5\%, pode-se afimar que não há diferença entre as médias, não havendo influência dessa característica da auditoria na qualidade de mensuração dos accruals.

Tabela 14 - Análise da influência de Serviços não Relacionados a Auditoria sobre a Qualidade da Mensuração dos Accruals

\begin{tabular}{l|r|r}
\hline & Outros Serviços & \multicolumn{1}{|c}{ Apenas Auditoria } \\
\hline Média & $-0,000$ & $-0,000$ \\
Desvio-Padrão & 0,754 & 1,0887 \\
& & \\
Observações & 187 & 795 \\
\hline & Statistic & -value \\
\hline Kolmogorov-Smirnov & 1,926 & 0,001 \\
Mann-Whitney U & $-0,826$ & 0,409 \\
\hline
\end{tabular}

Fonte: Própria

4.2.2.4 Análise da influência da existência de comitê de auditoria na companhia auditada sobre a qualidade na mensuração dos accruals

Os gestores das companhias podem apresentar comportamentos discricionários, aumentando o lucro através dos accruals. O comitê de auditoria em suas atribuições dentro de um sistema de governança, visa avaliar fiscalizar auditor independente, bem como não permitir que os gestores tenho comportamentos e tomada de decisões que venham a prejudicar o desempenho econômico e a integridade dos relatórios contábeis. Com isto, a presença do comitê de auditoria pode melhor a qualidade da mensuração dos accruals das companhias. Segue os resultados na tabela 15 abaixo: 
Tabela 15 - Análise da influência da Presença de Comitê de Auditoria sobre a Qualidade da Mensuração dos Accruals

\begin{tabular}{l|r|r}
\hline & Comitê & Sem Comitê \\
\hline Média & 0,000 & $-0,001$ \\
Desvio-Padrão & 0,793 & 0,943 \\
Observações & 256 & 726 \\
\hline Kolmogorov-Smirnov & Statistic & 0 -value \\
Teste de Levene & 1,333 & 0,167 \\
Teste t & 8,948 & 0,003 \\
ANOVA & 0,000 & 1,000 \\
Welch & 0,000 & 1,000 \\
Brown-Forsythe & 0,000 & 1,000 \\
\hline Fonte: Proppran & 0,000 & 1,000 \\
\hline
\end{tabular}

Fonte: Própria

Verifica-se que não é possível constatar diferença entre as médias dos dois grupos de empresas, aquelas que apresentam o comitê de auditoria e as que não apresentam. Com isto, estatisticamente a presença do comitê não melhora a qualidade da mensuração dos accruals contábeis.

4.2.2.5 Análise da influência do tempo de emissão do relatório de auditoria independente sobre a qualidade na mensuração dos accruals

A tabela 16 abaixo apresenta os resultados do efeito do tempo de emissão do relatório elaborado pelo auditor na qualidade da mensuração dos accruals. Para esta análise, foi separado dois grupos de tempo de emissão dos relatórios, aqueles que foram emitidos em até 90 dias e aqueles após esse período. Como a distribuição não mostrou-se normal, foi realizado o teste de média paramétrico de Mann-Whitney $U$, onde pode inferir que não há diferença estatística entre as médias dos dois grupos.

Tabela 16 - Análise da influência do Tempo de Emissão do Relatório de Auditoria sobre a Qualidade da Mensuração dos Accruals

\begin{tabular}{l|r|r}
\hline & Até 90 dias & Após 90 dias \\
\hline Média & 0,000 & 0,000 \\
Desvio-Padrão & 0,922 & 0,244 \\
& & 907 \\
Observações & Statistic & 75 \\
\hline Kolmogorov-Smirnov & 3,324 & p-value \\
Mann-Whitney U & $-0,243$ & 0,000 \\
\hline Fonte: Própria & & 0,808 \\
\hline
\end{tabular}

4.2.3 Análise da influência das características da auditoria independente sobre o value relevance

O terceiro e último atributo da qualidade da informação contábil analisado pelo presente estudo foi o value relevance. Conforme exposto no referencial teórico do presente trabalho, o value relevance refere-se ao impacto das informações reportadas pelas companhias na precificação das ações destas. Com isto, se verificou como características da auditoria independente podem impactar no preço das ações, sendo, desta forma, value relevants para a tomada de decisões. 
4.2.3.1 Análise da influência do tamanho da firma de auditoria independente sobre o value relevance

A primeira característica da auditoria a ser verificada a sua influência ou não na precificação das ações foi o tamanho da firma de auditoria $\left(\operatorname{AUDTAM}_{\mathrm{it}}\right)$, conforme exposto nos procedimentos metodológicos. Com base no modelo de Ohlson (1992), a tabela 17 apresenta os resultados da regressão:

\begin{tabular}{l|r|r} 
Tabela 17 - Análise da influência do Tamanho da Firma de Auditoria sobre o \\
Value Relavance \\
\hline & \multicolumn{1}{|c}{ Coef. } & \multicolumn{1}{c}{ p-value } \\
\hline Constante & 0,442 & 0,000 \\
$P L_{i t}$ & 0,570 & 0,000 \\
$L_{i t}^{a}$ & 1,962 & 0,000 \\
$A U D T A M_{i t}$ & 0,044 & 0,479 \\
& & \\
$\mathrm{R}^{2}$ & 0,765 & \\
$\mathrm{R}^{2}$ Ajustado & 0,152 & \\
$\mathrm{~F}(3,931)$ & 26,854 & 0,000 \\
Teste de Wald & 1,711 & 0,000 \\
Teste de Normalidade & 252,253 & 0,000 \\
$\mathrm{~N}$ & 1169 & \\
\hline
\end{tabular}

Fonte: Própria

Com base nos resultados da tabela 17, verifica-se que, tanto a patrimônio liquido quanto o lucro anormal, proposto pelo modelo de Ohlson (1992), impactam positivamente na precificação das ações a um nível de significância de 1\%, ou seja, quanto maior tais variáveis, maior será seu impacto positivo no preço das ações. Em relação ao tamanho da firma de auditoria, não foi possível verificar influencia significativa, onde pode-se inferir que o tamanho da firma da auditoria não impacta no preços das ações da companhia analisadas.

Era esperada influência positiva e significante na precificação das ações de companhias auditadas pelas Big 4, baseando-se na Teoria da Sinalização, pois os gestores das companhias podem utilizar de serviços de auditoria externa de firmas de auditoria maiores para sinalizar determinadas informações as agentes externos a companhia, as quais podem estar relacionadas com uma maior independência do auditor, bem como a própria competência do mesmo, uma vez que, conforme visto no referencial teórico, as firmas maiores de auditoria investem mais em treinamento dos seus colaboradores, sinalizando, de certo modo, um menor risco aos investidores, conforme defendido por Clarkson e Simunic (1994).

4.2.3.2 Análise da influência do tempo de relacionamento entre a firma de auditoria e o cliente sobre o value relevance

A quarta característica da auditoria independente analisada foi o tempo de relacionamento entre a firma de auditoria e o cliente $\left(\right.$ TENURE $\left._{i t}\right)$. As análises desta qualidade estão contidas na tabela 18 abaixo: 
Tabela 18 - Análise da influência do Período de Relacionamento entre a Firma de Auditoria e o cliente sobre o Value Relevance

\begin{tabular}{l|r|r}
\hline & Coef. & p-value \\
\hline Constante & 0,513 & 0,000 \\
PL $_{\text {it }}$ & 0,560 & 0,000 \\
$\mathrm{~L}_{\text {it }}^{\mathrm{a}}$ & 1,965 & 0,000 \\
TENURE $_{\text {it }}$ & $-0,015$ & 0,181 \\
& & \\
$\mathrm{R}^{2}$ & 0,765 & \\
$\mathrm{R}^{2}$ Ajustado & 0,154 & \\
$\mathrm{~F}(3,931)$ & 30,027 & 0,000 \\
Teste de Wald & 1,734 & 0,000 \\
Teste de Normalidade & 260,328 & 0,000 \\
$\mathrm{~N}$ & 1169 & \\
\hline
\end{tabular}

Fonte: Própria

Com base na tabela 18 acima, pode-se verificar que não há influência significativa no tempo de relacionamento entre a firma de auditoria e o seu cliente na precificação das ações da amostra analisada. Tal fato, pode ser devido a regulação das companhias abertas terem de realizar o rodizio dos auditores independentes, restrigindo o período de relacionamento em, no máximo, cinco anos consecutivos.

Porém, pode-se verificar que, apesar de não apresentar significância estatística, o coeficiente da variável TENURE it $_{\text {apresentou sinal negativo, o que pode indicar indícios }}$ de possível influência no preço das ações.

4.2.3.3 Análise da influência da realização de outros serviços não relacionados a auditoria pela firma de auditoria independente sobre o value relevance

A segunda característica independente a verificar o seu influência ou não na precificação das ações das companhias pertencentes a amostra foi se a firma de auditoria presta outros serviços não relacionados a auditoria para a companhia auditada. Esta característica está relacionada com a independência da firma de auditoria, uma vez que aufere receitas provenientes de outros serviços, o que, teoricamente, pode prejudicar na realização dos serviços de auditoria. Na tabela 19, apresenta os resultados da análise, conforme a equação 5:

\begin{tabular}{l|r|r}
\multicolumn{2}{c}{ Tabela 19 - Análise da influência dos Serviços não Relacionados a Auditoria } \\
sobre o Value Relevance
\end{tabular}

Fonte: Própria

Para esta característica da auditoria independente, esperava-se que a realização de serviços não relacionados a auditoria impactasse negativa no preço das ações, uma vez 
que os investidores poderiam questionar a independência do auditoria, bem como os relatórios e informações elaboradas pelo mesmo. Porém, pode-se verificar evidências de firma de auditoria que prestem outros serviços não relacionados a auditoria impactam positivamente no preço das ações, a um nível de significância de 5\%. Tal fato pode ser explicado por, apesar de comprometer a independência, visto que tem as firmas de auditoria têm uma maior realização de receitas, as firmas de auditoria acabam conhecendo melhor o funcionamento da empresa auditada, dependendo do tipo do outro serviço prestado.

Os resultados obtidos podem ter sido prejudicados pelo fato que de foi utilizado apenas uma variável dummy para a realização ou não de serviços não relacionados a auditoria. O montante pago pela realização destes serviços podem apresentar resultados mais precisos, porém, visto que a divulgação obrigatória de tais dados começou no ano de 2009, optou-se apenas em utilizar a variável dummy citada anteriormente.

4.2.3.4 Análise da influência da existência de comitê de auditoria na companhia auditada sobre o value relevance

A existência de comitê de auditoria $\left(\mathrm{AUDCOM}_{\mathrm{it}}\right)$ foi a terceira característica de auditoria analisada a sua influência na precificação das ações. Conforme exposto no referencial teórico, o comitê de auditoria, através de suas atribuições, é tratado na literatura como um fator que atribui maior independência na relação entre firma de auditoria e cliente, uma vez que, a contratação dos serviços de auditoria externa, bem como a fiscalização, possivelmente fica por conta do comitê, caracterizado por ser independente da administração da companhia.

\begin{tabular}{|c|c|c|}
\hline & Coef. & $p$-value \\
\hline Constante & 0,468 & 0,000 \\
\hline$P L_{i t}$ & 0,565 & 0,000 \\
\hline$L_{i t}^{a}$ & 1,952 & 0,000 \\
\hline$A U D C O M_{i t}$ & 0,041 & 0,557 \\
\hline $\mathrm{R}^{2}$ & 0,765 & \\
\hline $\mathrm{R}^{2}$ Ajustado & 0,152 & \\
\hline$F(3,931)$ & 26,589 & 0,000 \\
\hline Teste de Wald & 1,724 & 0,000 \\
\hline Teste de Normalidade & 252,309 & 0,000 \\
\hline $\mathrm{N}$ & 1169 & \\
\hline
\end{tabular}

Com base na tabela 20 anterior, pode-se verificar que a existência do Comitê de Auditoria não impacta na precificação das ações das companhias analisadas, apesar de amplamente discutido no âmbito da governança corporativa, principalmente em mercados de capitais mais desenvolvidos, como o mercado de capitais dos Estados Unidos.

4.2.3.5 Análise da influência do tempo de emissão do relatório de auditoria independente sobre o value relevance 
O tempo de emissão do relatório de auditoria $\left(\right.$ DELAY $\left._{i t}\right)$ foi a penúltima característica da auditoria analisada. Conforme exposto no referencial, esta característica pode sinalizar falhas no processo de auditoria, em caso de atraso na emissão do relatório do mesmo (MANDE; SON, 2011), mas, em caso de emissão de relatório com brevidade, pode sinalizar algum atributo da qualidade da informação contábil, conforme defendido por Paulo (2012). Os resultados da influência do tempo de emissão do relatório de auditoria sobre o value relevance estão nas tabelas 21 e 22, onde a primeira tabela leva em consideração a quantidade de dias para a emissão do relatório de auditoria após o término do exercício social, enquanto que na segunda tabela foram realizadas analises em três períodos de tempo (até 30 dias, até 90 dias e mais de 69 dias), com o intuito de verificar se a diferença temporal da emissão dos relatórios afetam a precificação das ações.

Tabela 21 - Análise da influência do Tempo de Emissão do Relatório de Auditoria sobre o Value Relevance

\begin{tabular}{l|r|r}
\hline \multicolumn{2}{c}{ Coef. } & p-value \\
\hline Constante & 0,441 & 0,000 \\
$\mathrm{PL}_{\text {it }}$ & 0,566 & 0,000 \\
$\mathrm{~L}_{\text {it }}^{\mathrm{a}}$ & 1,971 & 0,000 \\
DELAY $_{\text {it }}$ & 0,001 & 0,137 \\
$\mathrm{R}^{2}$ & & \\
$\mathrm{R}^{2}$ Ajustado & 0,765 & \\
$\mathrm{~F}(3,931)$ & 0,153 & 0,000 \\
Teste de Wald & 26,877 & 0,000 \\
Teste de Normalidade & 1,698 & 0,000 \\
$\mathrm{~N}$ & 255,001 & \\
\hline Fonte: Própria & 1169 &
\end{tabular}

Conforme exposto na tabela 21 acima, pode-se verificar que, não há influência do tempo de emissão do relatório de auditoria no value relevance das companhias. Apesar do que defendido por Mande e Son (2011), onde os autores afirmar que o atraso no serviço de auditoria pode significar alguém problema relacionado ao próprio serviço, os investidores, conforme análise realizada, não se utilizam desta informação para tomar suas decisões de investimentos. Porém, os pesquisadores da área devem buscar explicações não apenas baseada no tempo de emissão do relatório, mas atráves de outras características que possam até mesmo acarretar em um maior tempo para que o auditor emita a sua opinião.

Tabela 22 - Análise da influência do Tempo de Emissão do Relatório de Auditoria sobre o Value

\begin{tabular}{|c|c|c|c|c|c|c|}
\hline \multicolumn{7}{|c|}{ Relevance (segregados em grupos) } \\
\hline & \multicolumn{2}{|c|}{30 dias } & \multicolumn{2}{|c|}{90 dias } & \multicolumn{2}{|c|}{+90 dias } \\
\hline & Coef. & p-value & Coef. & p-value & Coef. & p-value \\
\hline Constante & 0,476 & 0,000 & 0,560 & 0,000 & 0,473 & 0,000 \\
\hline$P L_{i t}$ & 0,566 & 0,000 & 0,565 & 0,000 & 0,565 & 0,000 \\
\hline$L_{i t}^{a}$ & 1,959 & 0,000 & 1,972 & 0,000 & 1,972 & 0,000 \\
\hline$D E L A Y_{i t}$ & 0,036 & 0,718 & $-0,086$ & 0,114 & 0,086 & 0,114 \\
\hline $\mathrm{R}^{2}$ & 0,764 & & 0,765 & & 0,765 & \\
\hline $\mathrm{R}^{2}$ Ajustado & 0,152 & & 0,153 & & 0,153 & \\
\hline$F(3,931)$ & 27,4211 & 0,000 & 26,719 & 0,000 & 26,719 & 0,000 \\
\hline Teste de Wald & 1,720 & 0,000 & 1,480 & 0,000 & 1,492 & 0,000 \\
\hline Teste de Normalidade & 254,51 & 0,000 & 252,82 & 0,000 & 252,82 & 0,000 \\
\hline $\mathrm{N}$ & 1169 & & 1169 & & 1169 & \\
\hline
\end{tabular}


Fonte: Própria

Conforme exposto na tabela 22, pode-se verificar que nenhum período analisado apresentar influência na precificação das ações das companhias. Realizou-se tal análise para tentar verificar se tais diferencias temporais poderiam influenciar na precificação das ações, mediante as janelas de estimações (30 dias, 90 dias e mais de 90 dias). 


\section{CONSIDERAÇÕES FINAIS}

O presente trabalho teve como intuito verificar se as características relacionadas a auditoria independente impactam na qualidade da informação contábil. A auditoria independente, parte externa à companhia auditada, tem como objetivo atribuir maior grau de confiabilidade dos relatórios financeiros emitidos pela companhia, mediante a elaboração do relatório de auditoria independente, no qual expõem a sua opinião acerca de tais relatórios.

Face a todos os escândalos corporativos, bem como o crescimento de necessidades de serviços que visem atribuir menor risco aos agentes internos as empresas, principalmente por questões relacionadas a conflitos de agência e de assimetria informacional, a auditoria deve ser vista por tais agentes como importante, se não a principal, ferramento de asseguração a cerca das informações repassadas pelas companhias.

As estatísticas descritivas do estudo apresentam que a maioria das companhias analisadas não apresenta comitê de auditoria, onde tal fato pode prejudicar os serviços prestados pelos auditores, uma vez que tais serviços são fiscalizados pela própria administração, não tendo determinado setor independente para fiscalizar os auditores independentes. Por outro lado, a maioria da amostra não utilizou de outros serviços não relacionados a auditoria, o que pode-se inferir que melhora a independência do auditor, principalmente em termos econômicos. Porém, verificou-se, nas análises de resultados acerca do value relevance que as companhias auditadas por firmas que prestaram outros serviços de auditoria apresentaram maior influência na precificação das ações, valorizando as mesmas positivamente, o qual pode se justificar pelo fato de melhor conhecimento do auditor acerca das atividades da companhia. As demais características da auditoria não impactam no value relevance das companhias.

Tratando do conservadorismo contábil, os resultados deste estudo verificou que o tempo de relacionamento entre a firma de auditoria e o cliente impactam no nível de conservadorismo das companhias, podendo utilizar da mesma justificativa anterior para a influência do serviços de não auditoria no value relevance.

Ainda tratando do conservadorismo contábil, as companhias auditadas por firmas de auditoria que prestaram outros serviços não relacionados a auditoria são menos propensas a reconhecer oportunamente as perdas econômicas, ou seja, impactando negativamente no nível de conservadorismo. Com isto, verifica-se que o tratamento dado 
pela literatura, em torno da independência e competência da auditoria, deve haver uma melhor discussão acerca dos mesmos.

Em relação a qualidade da mensuração dos accruals, foi verificado que o tempo de relacionamento entre a firma de auditoria e o cliente melhora esta qualidade da informação contábil, corroborando com achados do trabalho de Myers, Myers e Omer 2003) e Chen, Lin e Lin (2008).

Para futuras pesquisas, sugere-se a criação de um índice que capte o conjunto de características da auditoria independente, bem como o conjunto de atributos da qualidade da informação contábil. Além disso, sugere-se que analisem a influência das características de auditoria independente sobre a qualidade da informação contábil em outros mercados com características similares ao Brasil, podendo haver comparação entre os mercados, buscando identificar as similiariedades entre estes, bem como verificar a importância dada a auditoria independente em outros países. As principais limitações deste trabalho foram a quantidade de dados ausentes, tanto relacionados a auditoria independente quanto aos dados financeiros, o que impossibilitou uma análise mais robusta, bem como a estimação por dados em painel balanceado, o qual poderia possibilitar encontrar evidências mais completas.

Apesar do analisado pela literatura, espera-se que os estudiosos e pesquisadores da área possam verificar a auditoria não apenas na concepção de independência e competência, uma vez que alguns achados deste estudo apresentam indícios de que características da auditoria independente que, teoricamente, implicariam em uma diminuição da qualidade da informação contábil baseada em independência, foi-se verificado que houve uma melhora na qualidade, podendo-se justificar pela apresentação de maior competência dos auditores. Além disso, deve-se analisar a prestação de serviços de auditoria em si, desde a estrutura das firmas de auditoria até o ambiente no qual o mesmo encontra-se inserido. 


\section{REFERÊNCIAS BIBLIOGRÁFICAS}

AL-AHMI, J. Audit and reporting delays: Evidence from an emerging market. Advances in Accounting, incorporating Advances in International Accounting, v. 24, p. 217226, 2008.

BALL, R.; SHIVAKUMAR, L. Earnings quality UK private firms: comparative loss recognition timeliness. Journal of Accounting and Economics. New York: v. 39, n.1, p. 83-128, feb. 2005.

BARTH, M. E. CRAM, D. P.; NELSON, K. K. Accruals and the predictions of future cash flows. The Accounting Review, v. 76. 2001.

; BEAVER, W. H.; LANDSMAN, W. R. The relevance of value relevance literature for financial accounting standard setting: another view. Journal of Accounting and Economics, v. 31, p. 77-104, 2001.

BASU, S. The conservatism principle and the asymmetric timeliness of earnings. Journal of Accounting and Economics. New York: v. 24, v.1, p. 3-37, dec. 1997.

BAUWHEDE, H. V.; WILLEKENS, M.; GAEREMYNCK, A. Audit firm size, public ownership, and firms' discretionary accruals management. The International Journal of Accounting, v. 38, p. 1-22, 2003.

BECKER, C. L.; DEFOND, M. L.; JIAMBALVO, J.; SUBRAMANYAM, K. R. The effect of audit quality on earnings management. Contemporary Accounting Research. Toronto: v. 15, n.1, p. 1-24, spring 1998.

BEHN, B. K.; CHOI, J.; KANG, T. Audit Quality and Properties of Analyst Earnings Forecasts, The Accounting Review, v. 83, n. 2, p. 327-349, 2009)

BEUREN, I. M. (org.). Como elaborar trabalhos monográficos em contabilidade: teoria e prática. 3. ed. São Paulo: Atlas, 2006.

; THEISS, V.; SANT'ANA, S. V. Conservadorismo Contábil no Reconhecimento de Ativos Intangíveis em Fase de Pesquisa e Desenvolvimento: Um Estudo em Empresas da BM\&FBovespa. Contabilidade, Gestão e Governança, v16, n. 1, p. 98-111, jan./abr. 2013.

BOYNTON, C. W.; JOHNSON, R. N.; KELL, G. W. Auditoria. 7. Ed. São Paulo: Atlas, 2002.

BRASIL. Lei $\mathbf{n}^{\circ}$ 6.385, de 7 de Dezembro de 1976. Dispões sobre o mercado de valores mobiliários e cria a Comissão de Valores Mobiliários.

Ações.

; Lei $\mathbf{n}^{\circ}$ 6.404, de 15 de Dezembro de 1976. Dispõe sobre as Sociedades por

BROOKS, C. Introductory econometrics for finance. 2 ed. Cambrigde: Cambrigde University Press, 2008. 
CERVO, A. L., BERVIAN, P. A. Metodologia científica. 5.ed. São Paulo: Prentice Hall, 2002 .

CHAHINE, S.; FILATOTCHEV, I. The effects of corporate governance and audit and non-audit fees on IPO Value. The British Accounting Review, v. 43, p. 155-172, 2011.

CHAN, R. S. Y.; LAU, C. K. S.; NG, A. W. Compliance and value relevance of audit committees: evidence from Hong Kong, Journal of Financial Reporting \& Accounting, v. 9, n. 1, p. 74-97, 2011.

CHEN, C.; LIN, C.; LIN, Y. Audit Partner Tenure, Audit Firm Tenure, and Discretionary Accruals: Does Long Auditor Tenure Impair Earnings Quality? Contemporary Accounting Research, v. 25, n. 2, p. 415-445, 2008.

CLARKSON, P. M.; SIMUNIC, D. A. The association between audit quality, retained ownership, and firm specific risk in U.S. vs. Canadian IPO markets. Journal of Accounting and Economics, v. 17, p. 207-228. 1994.

COELHO, A. C. D. Qualidade informacional e conservadorismo nos resultados publicados no Brasil. Tese de doutorado, Programa de Pós-graduação em Ciências Contábeis, Departamento de Contabilidade e Atuaria, Faculdade de Economia, Administração e Contabilidade da Universidade de São Paulo, São Paulo, SP, Brasil. 2007.

AGUIAR, A. B.; LOPES, A. B. Relationship between abnormal earnings persistence, industry structure, and market share in Brazilian public firms, Brazilian Administration Review, v.8, n.1, p.48-67, jan-mar, 2011.

COMISSÃO DE VALORES MOBILIÁRIOS. Instrução Normativa CVM no 308, de 14 de Maio de 1999. Dispõe sobre o registro e o exercício da atividade de auditoria independente no âmbito do mercado de valores mobiliários, define os deveres e as responsabilidades dos administradores das entidades auditadas no relacionamento com os auditores independentes, e revoga as Instruções CVM nos 216, de 29 de junho de 1994, e 275, de 12 de março de 1998.

CRASWELL, A. T.; FRANCIS, J. R.; TAYLOR, S. L. Auditor brand name reputations and industry specializations. Journal of Accounting and Economics, v. 20, p. 297-322, 1995.

CUPERTINO, C.; MARTINEZ, A. L. Qualidade da auditoria e earnings management risk assessment através do nível de accruals discricionários. Contabilidade Vista \& Revista, v. 19, p. 69-93, 2008.

DANTAS, J. A.; PAULO, E.; MEDEIROS, O. R. Conservadorismo Condicional na Indústria Bancária Brasileira em Situações de Maior Percepção de Risco. Revista Universo Contábil, v. 9, n. 2, p. 83-103, abr.jun. 2013.

DEANGELO, L. E. Auditor size and auditor quality. Journal of Accounting and Economics, v.3, p. 183-199, 1981. 
DECHOW, P. M.; DICHEV, I. D. The quality of accruals and earnings: the role of accrual estimation errors. The Accounting Review, Sarasota, v. 77, n.4, supplement, p.35-59, oct. 2002.

; GE, W.; SCHRAND, C. M. Understanding earnings quality: A review of the proxies, their determinants and their consequences. Journal of Accounting and Economics, New York: v.50, n. 2-3, p.344-401, dec. 2010.

DEFOND, M. L.; SUBRAMANYAM, K. R. Auditor changes and discretionary accruals. Journal of Accounting and Economics. New York: v. 25, n.1, p. 35-67, feb. 1998.

; JIAMBALVO, J. Debt convenant violation and manipulation of accruals. Journal of Accounting and Economics, v. 17, n. 1-2, p. 145-176, 1994.

; ZHANG, J. A review of Archival Auditing Research. Working Paper. University of Southern California, aug. 2014. Disponível em: 〈http://www.ssrn.com>. Acesso em: 06/10/2014.

FAMA, Eugene F.; FRENCH, Keneth R. The cross-section of expected stock returns. The Journal of Finance, v. XLVII, n.2, jun., 1992.

FARGHER, N.; TAYLOR, M. H.; SIMON, D. T. The demand for auditor reputation across international markets for audit services. International Journal of Accounting. v. 36, n. 4, p. 407-421, 2001.

FRANCIS, J. R. What do we know about audit quality? The British Accounting Review, v. 36, p. 345-368, 2004.

; KE, B. Disclosure of fees paid to auditors and the market valuation of earnings surprises. Review of Accounting Studies. v. 11, p. 495-523, 2006.

FURUTA, F. O. A relação das características das empresas com a adoção do comitê de auditoria x conselho fiscal adaptado. São Paulo, 2010. Tese (Doutorado em Ciências Contábeis) - Programa de Pós-Graduação em Ciências Contábeis, Departamento de Contabilidade e Atuária, Faculdade de Economia, Administração e Contabilidade da Universidade de São Paulo.

GIL, A. C. Métodos e Técnicas de Pesquisa Social. 6. ed. São Paulo: Atlas, 2008.

GIRÃO, L. F. A. P. Assimetria informacional, insider trading e avaliação de empresas: evidências no mercado de capitais brasileiro. João Pessoa, 2012. Dissertação (Mestrado em Ciências Contábeis) - Programa Multi-institucional e InterRegional de Pós-graduação em Ciências Contábeis.

GHOSH, A., MOON, D. Does auditor tenure impair audit quality. The Accounting Review. v. 80, n.2, p. 585-612. 2005.

GUL, F. A.; KIM, J.; QIU, A. A. Ownership concentration, foreign shareholding, audit quality, and stock price synchronicity: Evidence from China. Journal of Financial Economics. v. 95, n. 3, p. 425-442, 2010. 
HOUMES, R.; FOLEY, M.; CEBULA, R. J. Audit quality and overvalued equity. Accounting Research Journal, v. 26, n. 1, p. 56-74, 2013.

IATRIDIS, G. E. Accounting disclosures, accounting quality and conditional and unconditional conservatism. International Review of Financial Analysis, v. 20, p. 88102, 2011.

IUDÍCIBUS, S.; LOPES, A. B. (Coords.) Teoria Avançada da Contabilidade. São Paulo: Atlas, 2004.

JENSEN, M. C.; MECKLING, W. H. Theory of the firm: managerial behavior, agency costs and ownership structure. Journal of Financial Economics, v. 3. n. 4, p. 305-360, 1976.

JEONG, S. W.; RHO, J. Big Six auditors and audit quality: The Korean evidence. The International Journal of Accounting, v. 39, p. 175-196, 2004.

KLEIN, A. Audit Committee, board of diretor characteristics, and earnings management. Journal of Accounting and Economics, v. 33, 2002.

KOCH, C. W.; WEBER, M.; WÜSTEMANN, J. Can auditors be independent? experimental evidence on the effects of client type. European Accounting Review. p. 127. 2011.

KRISHNAN, G. The association between Big 6 auditor industry expertise and the asymmetric timeliness of earnings. Journal of Accounting, Auditing and Finance (in press), 2004.

LEE. H.; LEE, H. Do Big 4 audit firms improve the value relevance of earnings and equity? Managerial Auditing Journal, v. 28, n. 7, 2013.

LEVENTIS, S.; CARAMANIS, C. Determinants of audit time as a proxy of audit quality. Managerial Auditing Journal, v. 20, n. 5, p. 460-478, 2005.

LIMA, D. H. S.; RODRIGUES, J. M.; SILVA, C. A. T.; SILVA, J. D. G. Impacto do Nível de Evidenciação de Informações Contábeis sobre a Precificação de Ações no Contex to de Seleção Adversa: uma pesquisa experimental. Revista Brasileira de Gestão de Negócios. v. 14, n. 43, p. 159-175, abr/jun. 2012.

MANDE, V.; SON, M. Do audit delas affect cliente retention? Managerial Auditing Journal, v. 26, n. 1, p. 32-50, 2011.

MARTINEZ, A. L. Gerenciamento dos resultados contábeis: estudo empírico das companhias abertas brasileiras. São Paulo, 2001. Tese (Doutorado em Ciências Contábeis) - Programa de Pós-Graduação em Ciências Contábeis, Departamento de Contabilidade e Atuária, Faculdade de Economia, Administração e Contabilidade da Universidade de São Paulo. 
Detectando Earnings Management no Brasil: Estimando os Accruls Discricionários. Revista Contabilidade \& Finanças, v. 19, n. 46, p. 7-17, janeiro/abril 2008.

MOORE, D. A.; TETLOCK, P. E.; TANLU, L.; BAZERMAN, M. H. Conflicts of interest and the case of auditor independence: moral seduction and strategic issue cycling. Academy of Management Review. v. 36, n.1, p. 1-20, 2006.

MYERS, J., MYERS, L., OMER, T. Exploring the term of the auditor-client relationship and the quality of earnings: A case for mandatory auditor rotation. The Accounting Review, v. 78, n. 3, p. 779-799, 2003.

NEEDLES JR., B. E.; RAMAMOORTI, S.; SHELTON, S. W. The Role of International Auditing in the Improvement of International Financial Reporting. Advances in International Accounting, v. 15, p. 181-201, 2002.

NG, P. P. H.; TAI, B. Y. K. An Empirical Examination of The Determinants of Audit Delay in Hong Kong. British Accounting Review, v. 26, p. 43-59, 1994.

OHLSON, J. Earnings, book values and dividends in equity valuation. Contemporary Accounting Research, v. 11, n.2, p. 661-687, 1995.

OWHOSO, V. E.; MESSIER JR., W. F.; LYNCH JR., J. G. Error Detection by IndustrySpecialized Teams during Sequential Audit Review. Journal of Accounting Research, v. 40, n. 3, jun/2002.

PALMROSE, Z. V. Auditfees and auditor size: further evidence. Journal of Accounting Research, v. 24, n. 1, p. 97-110, 1986.

PAUlO, E. CAVALCANTE, P. R. N.; MELO, I. I. S. L. Qualidade das informações contábeis na oferta pública de ações e debentures pelas companhias abertas brasileiras. Brazilian Business Review, v. 9, n. 1, p. 1-26, jan-mar/2012.

PAULO, I. I. S. L. M. Conservadorismo da Informação Contábil: Análise da relação com as características qualitativas da auditoria independente. João Pessoa, 2012. Dissertação (Mestrado em Ciências Contábeis) - Programa Multi-institucional e InterRegional de Pós-graduação em Ciências Contábeis.

; CAVAlCANTE, P. R. N.; PAUlO, E. Relação entre Qualidade da Auditoria e Conservadorismo Contábil nas Empresas Brasileiras, v. 7, n. 3, p. 305327, jul./set. 2013.

PIOT, C. Auditing quality and earnings management in France Working Papers. Pierre Mendés France University, jul. 2005. Disponível em: <http://www.ssrn.com>. Acesso em: 27/02/2006.

RAINSBURY, E. A.; BRADBURY, M.; CAHAN, S. F. The impact of audit committee quality on financial reporting quality and audit fees. Journal of Contemporary Accounting \& Economics, v. 5, p. 20-33, 2009.

RICHARDSON, R. J. Pesquisa Social: Métodos e Técnicas. São Paulo: Atlas, 1999 
RODRÍGUEZ, M. C.; ALEGRÍA, S. S. The value of audit quality in public and private companies: evidence from Spain, Journal of Management and Governance, v. 16, n. 4, p. 683-706, 2012.

RUDDOCK, C.; TAYLOR, S. J.; TAYLOR, S. L. Nonaudit services and earnings conservatism: Is auditor independence impaired? Contemporary Accounting Research. v.23. 2006.

SANTOS, A. C.; SOUZA, M. A.; MACHADO, D. G.; SILVA, R. P. Auditoria Independente: Um Estudo dos Pareceres Emitidos sobre Demonstrações Contábeis de Empresas Brasileiras Listadas na Bovespa e na NYSE. Revista Universo Contábil, v. 5, n. 4, p. 44-62, out./dez. 2009.

SILVA, A. G.; ROBLES JUNIOR, A. Os impactos na Atividade de Auditoria Independente com a Introdução da Lei Sarbanes-Oxley, Revista de Contabilidade e Finanças, v. 19, n. 48, p. 112-127, 2008.

SPENCE, M. Job Market Signaling. The Quarterly Journal of Economics, v. 87, n. 3, 1973.

SUBRAMANYAM, K. R. The pricing of discretionary accruals. Journal of Accounting and Economics, New York, v. 22, n. 1-3, p. 249-281, aug-dec. 1996.

SUN, J.; LIU, G. Auditor industry specialization, board governance, and earnings management. Managerial Auditing Journal, v. 28, n. 1, p. 45-64, 2013.

WATTS, R. L. Conservatism in accounting part I: explanations and implications. Accounting Horizons, v. 17, n. 3, p. 207-221, 2003.

1986.

; ZIMMERMAN, J. L. Positive accounting theory. New Jersey: Prentice Hall,

WOOLDRIDGE, J. M. Introductory econometrics: a modern approach. Mason, Ohio: Thomson, 2003.

YAMAMOTO, M. M.; SALOTTI, B. M. Informação Contábil: Estudos sobre a sua Divulgação no Mercado de Capitais. São Paulo: Atlas, 2006. 